\title{
Visuospatial versus Visuomotor Activity in the Premotor and Prefrontal Cortex of a Primate
}

\author{
Giuseppe di Pellegrino a and Steven P. Wise \\ Laboratory of Neurophysiology, National Institute of Mental Health, Poolesville, Maryland 20837
}

\begin{abstract}
When visuospatial stimuli instruct a limb movement, the stimulus can be said to have both sensory and sensorimotor aspects. We studied the premotor and prefrontal areas of a rhesus monkey in order to identify neuronal activity related to the motor (or instructional) aspects of such stimuli. A rhesus monkey chose limb-movement targets according to one of two rules: (1) visuospatial stimuli instructed and triggered a limb movement toward their locations or (2) identical stimuli triggered a movement toward a predetermined target regardless of their location. Gaze and head fixation assured that each stimulus appeared at a constant location in both retinocentric and craniocentric coordinates, as well as in allocentric space. The task required that the spatial location cued by certain stimuli had to be either remembered or attended after stimulus presentation and before movement. Thus, the visuospatial information presented under one rule differed from that presented under the other only in its motor (instructional) significance and not in its attentional, spatial, mnemonic, or strictly sensory aspects. We could thereby test and confirm the hypothesis that the motor significance of visuospatial cues should commonly affect neuronal activity in the premotor cortex, but less commonly do so in the prefrontal cortex.
\end{abstract}

[Key words: motor system, premotor cortex, visually guided movement, frontal lobe, prefrontal cortex, motor set]

Neurons in both the dorsolateral prefrontal cortex (PF) and the dorsal premotor cortex (PM) have discharge modulations closely correlated with visually guided movements. PM neurons related to spatially organized skeletomotor behavior (Kubota and Hamada, 1978; Godschalk et al., 1981, 1985; Weinrich and Wise, 1982; Godschalk and Lemon, 1983; Weinrich et al., 1984; Wise and Mauritz, 1985; Gentilucci et al., 1988; Kurata and Wise, 1988a; Riehle and Requin, 1989; Sasaki et al., 1990; Bauswein et al., 1991; Hocherman and Wise, 1991; Mushiake et al., 1991; Werner et al., 1991; Fogassi et al., 1992) are almost all selective for a particular direction of limb movement (Vaadia et al., 1986; Caminiti et al., 1990, 1991; Crammond and Kalaska, 1990, 1991; Burnod et al., 1992; see also Georgopoulos

Received June 23, 1992; revised Sept. 15, 1992; accepted Sept. 22, 1992.

We thank Mr. William Burriss for his assistance. We also thank Dr. Eilon Vaadia for his critical reading of the manuscript. G.dP. was supported by the Fogarty Center for International Study and the National Institute of Mental Health Intramural Research Program.

Correspondence should be addressed to Steven P. Wise, Laboratory of Neurophysiology, N.I.M.H., P.O. Box 289, Poolesville, MD 20837.

aresent address: Clinica Neurologica, Universita di Modena, Via Del Pozzo, 71-41100 Modena, Italy.

Copyright (C) 1993 Society for Neuroscience $0270-6474 / 93 / 131227-17 \$ 05.00 / 0$ et al., 1982, for primary motor cortex). PF neurons also discharge during visuospatially guided limb movements (Fuster and Alexander, 1971; Kubota and Niki, 1971; Niki, 1974a-c; Niki and Watanabe, 1976; Kojima and Goldman-Rakic, 1982, 1984; Kubota and Funahashi, 1982), and they show directional selectivity in both limb-movement (Vaadia et al., 1986) and oculomotor tasks (Funahashi et al., 1989, 1990, 1991; see also Bruce and Goldberg, 1985, for frontal eye field).

A long-standing problem in the study of these cortical fields concerns whether directionally selective activity reflects visuospatial information processing or the selection and guidance of movement direction. Visuomotor tasks employed in most previous studies were ambiguous in this regard because the location of the target stimulus and the end point of the movement necessary to acquire it coincided (see, e.g., Weinrich and Wise, 1982; Wise and Mauritz, 1985; Funahashi et al., 1989, 1990, 1991). Only a few studies have dissociated the spatial features of stimuli from those of the limb movements needed to acquire those targets (Niki and Watanabe, 1976; Vaadia et al., 1986; Alexander and Crutcher, 1990b; Crammond and Kalaska, 1990; Funahashi and Goldman-Rakic, 1990). We examined whether the motor instructional significance of otherwise identical visuospatial stimulus affects neural activity comparably in two frontal cortical regions.

An abstract (di Pellegrino and Wise, 1991b) and a preliminary note (Wise et al., 1992) concerning aspects of this work have been previously reported.

\section{Materials and Methods}

Subject and apparatus. A $6 \mathrm{~kg}$ male rhesus monkey (Macaca mulatta) sat in a primate chair, with its head firmly fixed, $9 \mathrm{~cm}$ from the front edge of a bit-pad digitizing tablet $(60 \mathrm{~cm}$ wide $\times 53 \mathrm{~cm}$ deep) inclined $15^{\circ}$ toward the monkey's shoulder. Nine light-emitting diodes (LEDs) were embedded in $45 \mathrm{~cm} \times 45 \mathrm{~cm}$ clear plastic display board parallel to the bit pad. Approximately $8.5 \mathrm{~cm}\left(18^{\circ}\right.$ of visual space) separated the central LED from eight peripheral LEDs placed at $45^{\circ}$ intervals. Figure 1 shows our spatial convention: we designated the LED nearest the monkey as $0^{\circ}$ and position 1; the other circumferential LED locations were numbered consecutively and counterclockwise from that position. Between the bit pad and display board $(10 \mathrm{~cm})$, a vertically oriented, cylindrical handle $(6 \mathrm{~cm}$ high, $1.5 \mathrm{~cm}$ diameter) pivoted on an axis attached to and directly over a bit-pad reading coil. A two-joint, articulated lever supported this assembly and allowed horizontal movements constrained to two dimensions, but unconstrained within the bit-pad work space.

Eye position was monitored with an infrared oculometer (Bouis Instruments) positioned in front of the left eye. Both eye position and limb position were digitized at $100 \mathrm{samples} / \mathrm{sec}$ and recorded occasionally during the several months of recording neuronal activity. Each day the oculomotor position signal was adjusted by having the monkey fixate the central LED and detect its dimming, which we termed the fixation task. Upon detection, the monkey had $650 \mathrm{msec}$ to move the handle to the LED position directly away from monkey (position 5). 


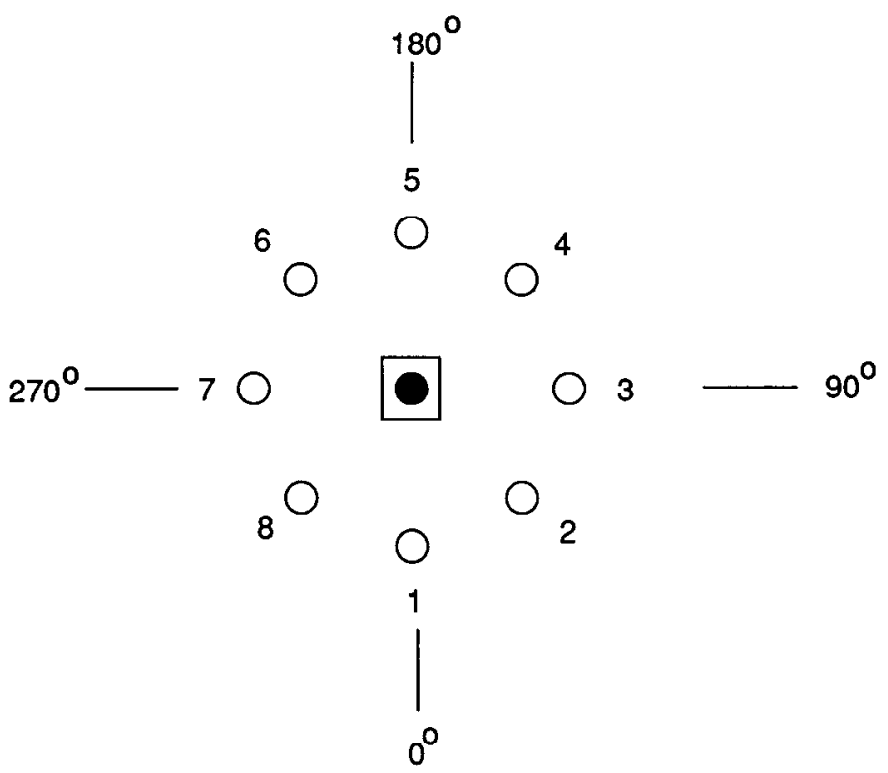

Figure 1. Facsimile of the LED panel showing the designation of positions and angles.

Behavioral paradigm. The monkey used its right hand to grasp the manipulandum, while it abducted its right arm. After an intertrial period $(1.8 \mathrm{sec})$, a trial began when the monkey brought the top of the handle beneath the central LED $( \pm 1.2 \mathrm{~cm})$ and fixated the central LED $\left( \pm 3.7^{\circ}\right)$ (Fig. 2, part 1).

After $800 \mathrm{msec}$ of steady posture and gaze, one of the eight peripheral LEDs illuminated for $500 \mathrm{msec}$ (Fig. 2, part 2) as the first prime stimulus (PS1). Next, from zero to four of the remaining seven peripheral LEDs illuminated for $100 \mathrm{msec}$ as distractor stimuli (DS), each DS separated from PS1 offset or the prior DS by either $550 \mathrm{msec}$ or $750 \mathrm{msec}$. No DS was repeated during a trial (Fig. 2, parts 3-6). The PS1 and DS locations, as well as the number of DS events on any given trial, were pseudorandomly selected. During this delay period, which ranged from $0.95 \mathrm{sec}$ to $4.65 \mathrm{sec}$, the monkey had to maintain a constant handle position and gaze angle. At the end of the delay period, the prime stimulus LED illuminated again for $100 \mathrm{msec}$ (Fig. 2, part 7), an event termed the second prime stimulus (PS2). PS2 onset triggered a handle movement to a target window $( \pm 1.2 \mathrm{~cm})$ centered beneath the target LED. PS2 onset also released the gaze requirement.

The appropriate choice of limb-movement target differed according to two different rules, which defined two conditions. In the compatible condition, the limb-movement target was the PS location (Fig. 2, part 8 , top). Thus, the monkey had to choose from eight possible movements. In the incompatible condition, the monkey had to attend to or remember the PS location and trigger the movement exactly as in the compatible condition, but the target was always position $5\left(180^{\circ}\right)$, regardless of PS location (Fig. 2, part 8, bottom).

The monkey received an approximately $0.2 \mathrm{ml}$ apple juice reward if the handle entered the correct target window within $650 \mathrm{msec}$ of PS2 onset. No constraints were imposed on the return movement, by which the monkey brought the handle back to the origin position to begin the next intertrial interval.

The monkey first learned the compatible condition, and then learned to fixate the central LED and perform the incompatible condition. During training, the two conditions alternated in blocks of approximately 100 correctly executed trials. While recording neuronal activity, we alternated conditions more frequently, beginning with approximately 50 trials in one condition, changing to about 50 trials in the other condition, and returning to the original condition for 25-50 trials. There were no cues concerning condition other than reward or nonreward on the previous trial.

Number of subjects. The present study compares PF and PM in a single animal, and thus the difference between these regions can be considered more decisive than comparisons between individuals. Because we could not successfully condition another monkey to perform all parts of this difficult task, we open the possibility that a peculiarity in that monkey's strategy influenced our result. However, we know of neither a reason to assume such peculiarity nor any way to eliminate the possibility that additional monkeys would adopt a similar strategy.

Behavioral analysis. We calculated reaction time as the interval between PS2 onset and the first movement of the handle exceeding 0.5 $\mathrm{cm}$ (see Fig. 3), and movement time as the interval from the onset of movement until the handle entered the target window (target acquisition).

Recordings. Glass-coated, elgiloy microelectrodes (1-3 M $\Omega$ ) were used to isolate the activity of individual neurons in the monkey's left hemisphere. We used conventional single-neuron recording techniques, including a time base-amplitude discriminator. The electrodes were inserted through a $36 \times 27 \mathrm{~mm}$ stainless steel recording chamber placed over the dura matcr. Handle position was monitored at 100 samples/ $\mathrm{sec}$ with a spatial resolution of $0.1 \mathrm{~mm}$.

The electromyographic (EMG) activity of hand, arm, shoulder, neck and trunk muscles was recorded, near the end of the recording sessions, with stainless steel electrodes. Muscles monitored on the right side included brachialis, triceps, biceps, supraspinatus, latissimus dorsi, trapezius, deltoid, infraspinatus, extensor carpi ulnaris, pectoralis major, extensor carpi radialis, thoracic paravertebral muscles, brachioradialis, flexor carpi ulnaris, quadriceps, gastrocnemius, and tibialis anterior. We examined triceps, trapezius, cervical paravertebral, and lumbar paravertebral muscles bilaterally. EMG signals were amplified, filtered with a band pass of $10 \mathrm{~Hz}$ to $10 \mathrm{kHz}$, rectified, integrated, and recorded as an analog signal (100 samples/sec).

Neuronal data analysis. Neuronal discharge during each trial was divided into six task periods: (1) a reference period consisting of the $800 \mathrm{msec}$ ending $200 \mathrm{msec}$ before trial initiation; (2) an anticipatory period, which consisted of $600 \mathrm{msec}$ immediately preceding PSI; (3) a prime stimulus period, which lasted the $500 \mathrm{msec}$ of PSl presentation; (4) a delay period (whole), beginning from the offset of the prime stimulus and lasting the variable time until PS2 onset; (5) a part of the delay period (end), lasting $300 \mathrm{msec}$ and terminating $200 \mathrm{msec}$ before movement onset; and (6) a premovement period, consisting of the final 200 msec before the onset of movement. Activity during period 3 corresponds to signal-related activity; that during periods 4 and 5 , to setrelated activity; and that during period 6 , to movement-related activity, as defined previously (Weinrich and Wise, 1982). An instance represents the activity of one neuron in one of these task periods.

For analysis of EMG activity, the same task periods were studied, except that (1) the movement period lasted $100 \mathrm{msec}$ longer, that is, from $200 \mathrm{msec}$ before until $100 \mathrm{msec}$ after the onset of movement, and (2) activity during and for $500 \mathrm{msec}$ after PSI offset substituted for periods 3 and 4 , above. The muscle activity measure consisted of the EMG signal integrated over the defined task period and divided by its duration.

Both neuronal activity and behavioral and EMG data were analyzed by a three-factor analysis of variance (ANOVA) with two conditions, eight PS locations, and a comparison of activity in the defined task period with reference activity $(\alpha=0.05)$. Post-hoc test involved paired comparisons (Tukey/Kramer). A separate two-factor ANOVA (eight PS locations and task period vs reference period) was performed for the incompatible condition. All analyses of variance were conducted using SYSTAT (L. Wilkinson, SYSTAT, Inc., Evanston, IL). A condition effect (CE) index was computed for each task period: $\mathrm{CE}=C_{\max } /\left(C_{\max }+I_{\max }\right)$, where $C_{\max }$ equals the mean activity for the PS location having the greatest activity in the compatible condition and $I_{\max }$ equals the analogous value for the incompatible condition. We also calculated the preferred direction of each cells in each task period by vector summation of the activity for each of the eight PS locations and compared this directional selectivity in the different conditions and task periods.

Histology. Near the end of recording single-neuron data, electrolytic lesions $(10 \mu \mathrm{A}$ for $10 \mathrm{sec}$, cathodal current) were made at six sites. After the termination of the recording sessions, each monkey was deeply anesthetized with sodium pentobarbital and perfused through the heart with aldehyde fixatives. During the perfusion, steel pins were inserted at known coordinates. The brain was photographed, sectioned on a freezing microtome at $40 \mu \mathrm{m}$ thickness, mounted on glass slides, and stained for Nissl substance with thionin.

Surface projections of the recording sites and the estimated track of each penetration was plotted by reference to the four recovered electrolytic lesions and to the pin holes. No attempt was made to identify each recording track in the histological material or to determine the depth of recording for any cell. Previously described cytoarchitectonic criteria (Weinrich and Wise, 1982; Wise, 1984, 1985) were used to distinguish PM (parts of area 6) from M1 (area 4). 

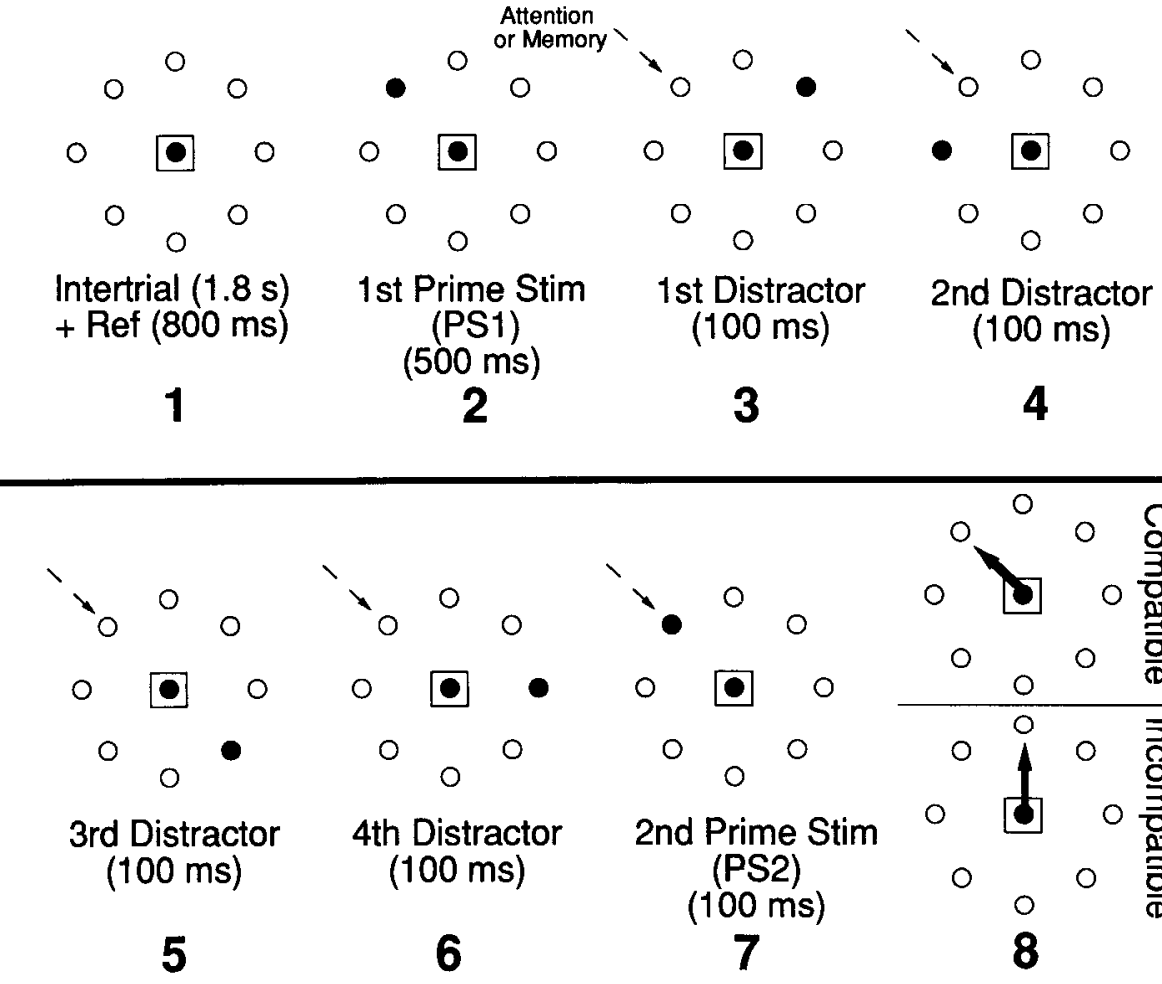

\section{Results}

\section{Behavior}

Kinematic analysis showed that each of the eight movements was clearly distinct from the others in the compatible condition. Four of these movement are shown in Figure 3. By contrast, in the incompatible condition, movements followed a nearly identical trajectory regardless of PS location (Fig. 3), and the variation that existed did not depend on PS location. After target acquisition, the monkey quickly returned to the central location and held limb posture relatively constant through most of the reference, intertrial, and delay periods. The monkey's oculomotor behavior appeared stereotyped and surprisingly similar in the two conditions (not shown). The monkey maintained gaze tightly centered on the central LED in both conditions. Because the movement was always away from the monkey in the incompatible condition, and therefore upward in its visual field, we expected that the monkey would look upward in that condition. But in the compatible condition, the limb-movement targets varied and the monkey could have looked toward the target after PS2 offset. Instead, the monkey virtually always made an upward saccade after the second PS presentation, as in the incompatible condition. Because the central LED was in the lower visual field of the monkey, it appears likely the monkey returned gaze to a central orbital position at the end of each trial, regardless of the task condition. After the end of the trial, the monkey most often returned gaze to a roughly neutral position.

The reaction times of the monkey varied significantly by condition $[F(1)=400 ; p<0.001$; three-factor ANOVA] and by PS location $[F(7)=23.4 ; p<0.001]$ (Table 1 ). Post hoc tests showed that the reaction times for responses to position $3\left(90^{\circ}\right)$ in the compatible condition differed significantly from those for most or all other movement directions in the compatible con-

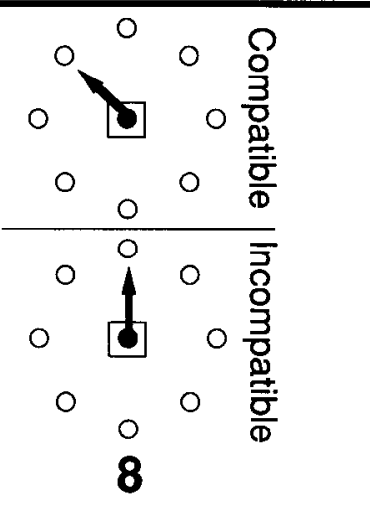

Figure 2. Behavioral paradigm and schematic of visual display for one of the eight possible PS locations. Each part $(I-8)$ shows a sketch of the panel; each circle represents an LED. Solid circles indicate illuminated LEDs, and the square around the central LED represents the fixation window (which was invisible to the monkey). The eight parts of the figure present the major events of the task in the order they occurred, but note that events 3- 6 did not all happen each trial and LEDs other than those illustrated may have been illuminated. The broken arrows represent the location that the monkey had to remember or attend to during the period between PS presentations. The solid arrows show the direction of forelimb movement in the two conditions. dition. There was also an effect of PS location on movement time $[F(7)=13.0 ; p<0.001]$, which was mainly due to the compatible condition, but this was much less dramatic than the difference in reaction time (Table 1). Movement times showed no condition effect $[F(1)=0.375 ; p=0.54]$.

In general, muscles were relatively inactive during the anticipatory, prime stimulus, and delay period and they increased activity just before or during the onset of the limb movement (Fig. 4). In the compatible condition (Fig. 4, left), EMG activity differed in magnitude and timing of according to locations of the prime stimulus (and therefore of the movement target). In the incompatible condition (Fig. 4, right), EMG activity was the same regardless of PS location. For trunk muscles, the activity usually began a little before the onset of movement and continued throughout the movement and intertrial period, including during the time the monkey returned the handle to the central position. In those muscles, EMG activity typically continued for all of the PSI period and part of the delay, though there was substantial trial-by-trial variability. ANOVA showed that there were effects of condition in all task periods, but the patterns EMG activity in the anticipatory, prime stimulus, and delay periods differed from the patterns of neuronal activity and lacked the dramatic modulations observed in both PM and PF neurons. Further, in these early parts of each trial, no muscle showed the directional selectivity that was the rule in the neuronal population.

\section{Neuronal activity}

Neuronal population and general properties. We recorded 94 task-related cells from the dorsal part of the PM and 54 neurons from the dorsolateral PF. The patterns of activity observed in relation to the task agree with those previously reported (e.g., Fuster, 1973; Godschalk et al., 1981; Weinrich and Wise, 1982; Vaadia et al., 1986; Riehle and Requin, 1989), and accordingly, 


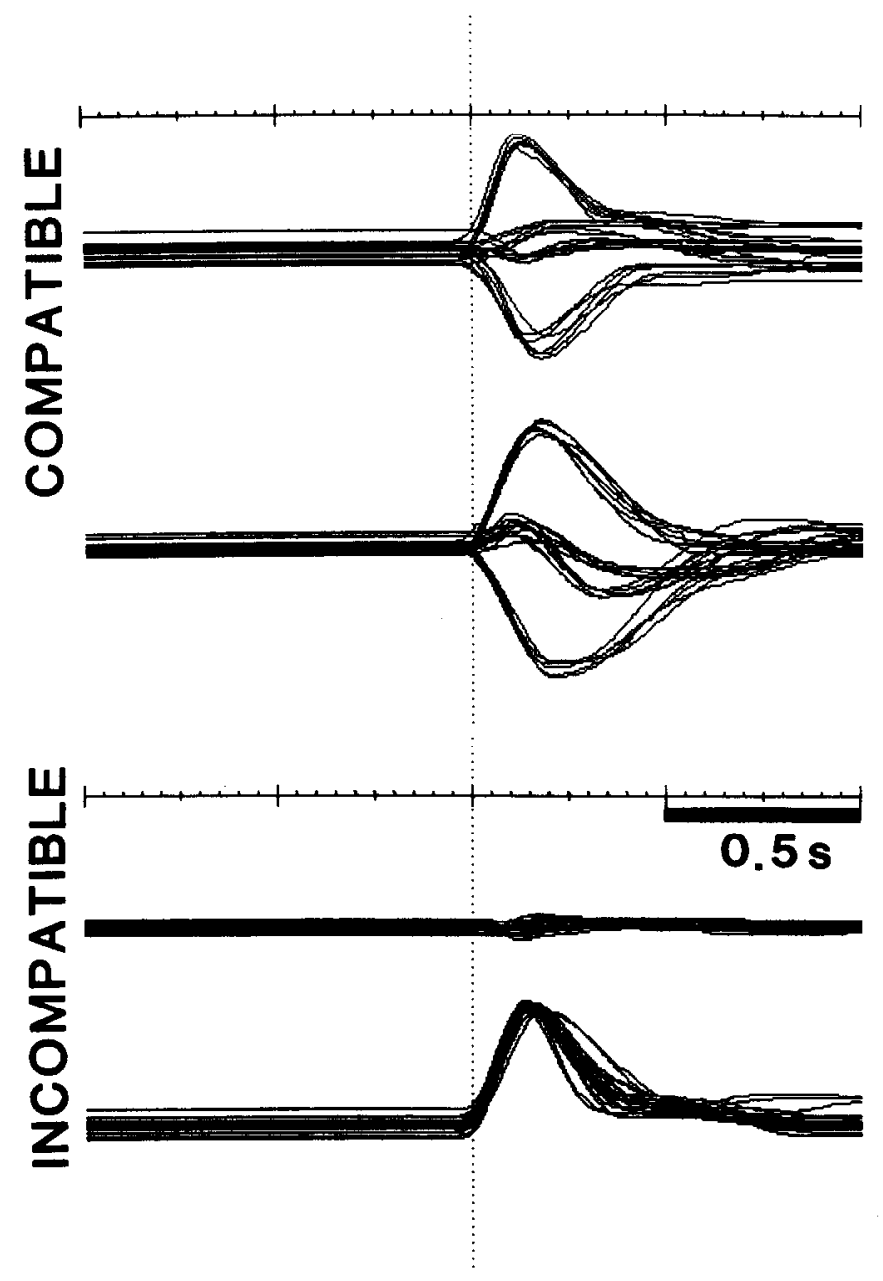

Figure 3. Limb position records in the two conditions. Each pair of position records superimposes several traces, with the $x$-coordinate on top and the $y$-coordinate on bottom. All movement records are aligned on the onset of movement (broken vertical line). Top, Compatible condition for four PS locations, supcrimposcd. Bottom, Incompatible condition for the same four PS locations. Note the stability during the period before the PS presentations. Time scale: major divisions, $0.5 \mathrm{sec}$; minor divisions, $50 \mathrm{msec}$.

we will not describe those activity patterns in detail here. The number of cells with significant activity in each task period is given in Table 2.

Activity after PS1, PS2, and during the delay period showed

Table 1. Reaction and movement times for the two conditions

\begin{tabular}{|c|c|c|c|c|}
\hline \multirow[b]{2}{*}{$\begin{array}{l}\text { PS } \\
\text { location }\end{array}$} & \multicolumn{2}{|c|}{$\begin{array}{l}\text { Reaction time } \\
(\mathrm{msec} \pm \mathrm{SD})\end{array}$} & \multicolumn{2}{|c|}{$\begin{array}{l}\text { Movement time } \\
(\mathrm{msec} \pm \mathrm{SD})\end{array}$} \\
\hline & Compatible & $\begin{array}{l}\text { Incom- } \\
\text { patible }\end{array}$ & Compatible & $\begin{array}{l}\text { Incom- } \\
\text { patible }\end{array}$ \\
\hline $1\left(0^{\circ}\right)$ & $284 \pm 14$ & $307 \pm 17$ & $100 \pm 16$ & $86 \pm 11$ \\
\hline $2\left(45^{\circ}\right)$ & $269 \pm 20$ & $303 \pm 21$ & $80 \pm 12$ & $87 \pm 12$ \\
\hline $3\left(90^{\circ}\right)$ & $258 \pm 17$ & $299 \pm 23$ & $84 \pm 14$ & $84 \pm 19$ \\
\hline $4\left(135^{\circ}\right)$ & $278 \pm 28$ & $286 \pm 20$ & $87 \pm 19$ & $83 \pm 16$ \\
\hline $5\left(180^{\circ}\right)$ & $284 \pm 20$ & $279 \pm 20$ & $85 \pm 12$ & $85 \pm 13$ \\
\hline $6\left(225^{\circ}\right)$ & $277 \pm 20$ & $284 \pm 17$ & $79 \pm 15$ & $94 \pm 31$ \\
\hline $7\left(270^{\circ}\right)$ & $279 \pm 19$ & $297 \pm 25$ & $94 \pm 12$ & $90 \pm 17$ \\
\hline $8\left(315^{\circ}\right)$ & $284 \pm 19$ & $302 \pm 19$ & $85 \pm 21$ & $89 \pm 14$ \\
\hline Range $(N)$ & $151-163$ & $101-109$ & $151-163$ & $101-109$ \\
\hline
\end{tabular}

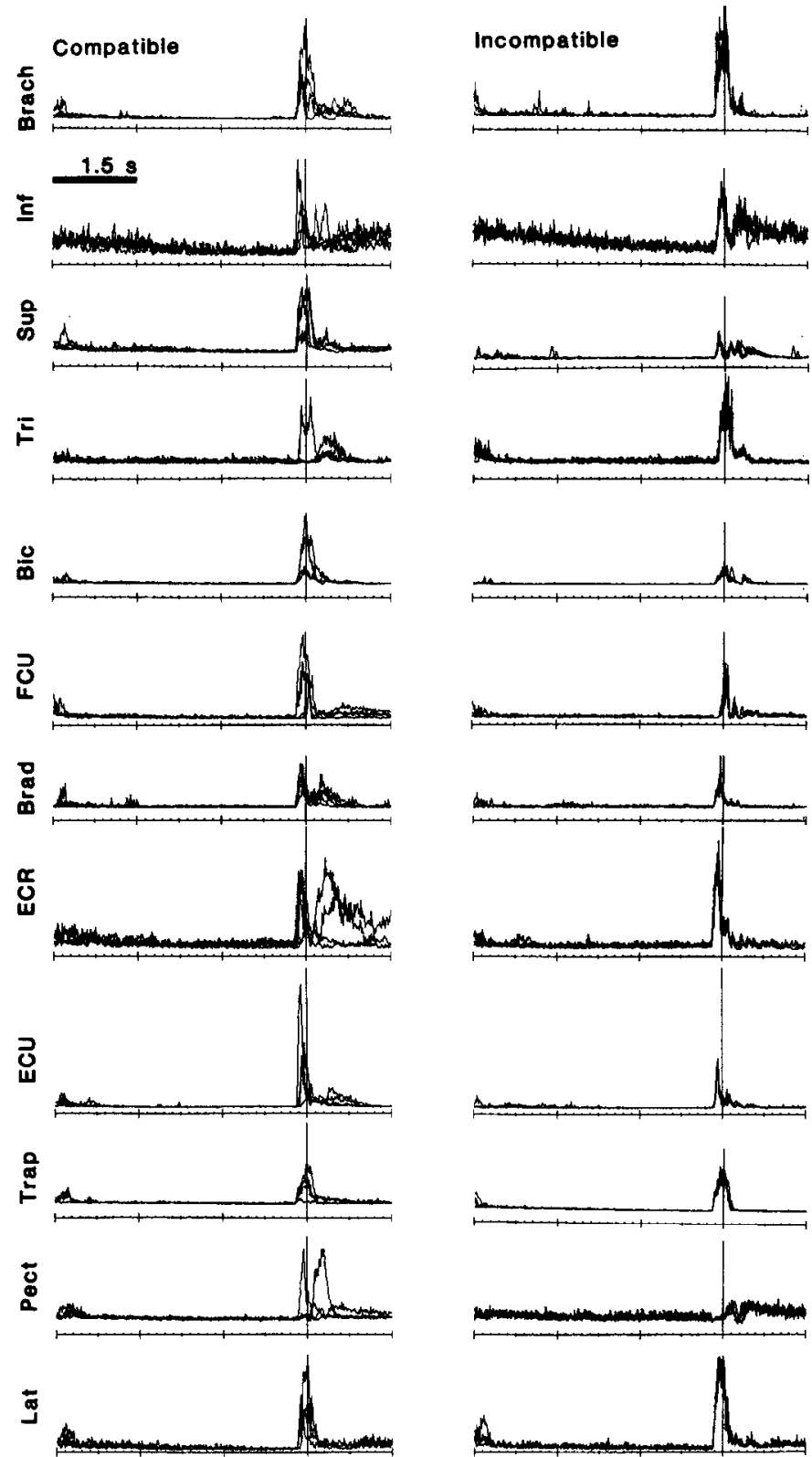

Figure 4. Sample of average EMG records. Left column, compatible condition; right column, incompatible condition. For each muscle, superimposed traces are shown for four PS locations. Note that EMG activity varies for the different average traces in the left column but superimpose closely in the right column. Brach, brachialis; Inf, infraspinatus; Sup, supraspinatus; Tri, triceps; Bic, biceps; $F C U$, flexor carpi ulnaris; $B r a d$, brachioradialis; $E C R$, extensor carpi radialis; $E C U$, extensor carpi ulnaris; Trap, trapezius; Pect, pectoralis; Lat, latissimus dorsi.

directional selectivity. The PS location associated with the greatcst activity was dcfined as the cell's preferred direction (from the central fixation point). Individual cells had preferred directions in all quadrants of the work space. Most PM cells showed unimodal directional selectivity curves in all task periods studied, as reported previously for the delay and premovement periods (Caminiti et al., 1990, 1991; Crammond and Kalaska, 1990, 1991). In PF, we could confirm the spatial selectivity reported previously in both skeletomotor and oculomotor tasks (Vaadia et al., 1986; Funahashi et al., 1990). 
Table 2. Numbers and percentage of cells with an effect of condition (two-factor ANOVA, $\alpha=0.05$ )

in the PM and PF cortex, by task period

\begin{tabular}{llllll} 
& & \multicolumn{3}{c}{ CE $>$} \\
Task period & PM & CE $>0.67 /$ & \multicolumn{2}{c}{$0.67 /$} \\
Anticipatory & $51 / 76(67 \%)^{* *}$ & $20 / 5$ & $17 / 41(41 \%)$ & $1 / 3$ & $\chi^{2}=7.2, p=0.007$ \\
Prime stimulus & $63 / 81(78 \%)^{* * *}$ & $23 / 5$ & $15 / 42(36 \%)$ & $1 / 4$ & $\chi^{2}=21.1, p=0.0001$ \\
Whole delay & $50 / 80(63 \%)^{*}$ & $18 / 9$ & $16 / 42(38 \%)$ & $4 / 2$ & $\chi^{2}=6.6, p=0.01$ \\
End delay & $46 / 75(61 \%)^{*}$ & $11 / 10$ & $13 / 33(39 \%)$ & $1 / 2$ & $\chi^{2}=4.4, p=0.035$ \\
Movement & $63 / 81(78 \%)^{* * *}$ & $15 / 11$ & $22 / 47(47 \%)$ & $7 / 3$ & $\chi^{2}=12.8, p=0.0003$
\end{tabular}

Only cells with significant activity differences from the reference period were included. Asterisks indicate the level of significant difference between PM and PF. CE, condition effect index. The table gives the numbers of cells with $\mathrm{CE}$ greater than 0.67 and less than 0.33 . These values represent activity in the compatible condition that is double or half that in the incompatible condition, respectively.

A cell's preferred direction could differ by task period. Figure 5 shows a PM cell that had $111^{\circ}$ difference in its directional preference for the PS1 period versus the delay period in the compatible condition. For PM cells, the preferred directions for activity immediately after PSI onset (post-PSI activity) differed by a mean absolute value of $62^{\circ} \pm 50^{\circ}(N=74)$ from those during the delay period. Preferred direction differed by $55^{\circ} \pm$ $50^{\circ}(N=70)$ between the delay period and the premovement period. In PF, post-PS1 and delay-period preferred directions differed by $79^{\circ} \pm 54^{\circ}(N=27)$, whereas delay and premovement selectivity differed by $47^{\circ} \pm 51^{\circ}(N=30)$. These values did not differ markedly by condition.

Condition effects. Figures 6-9, taken from three different PM neurons, show typical examples of a condition effect for the anticipatory period (Fig. 6), the prime stimulus period (Fig. 7), and the delay period (Figs. 8,9 ). Similar condition effects oc-
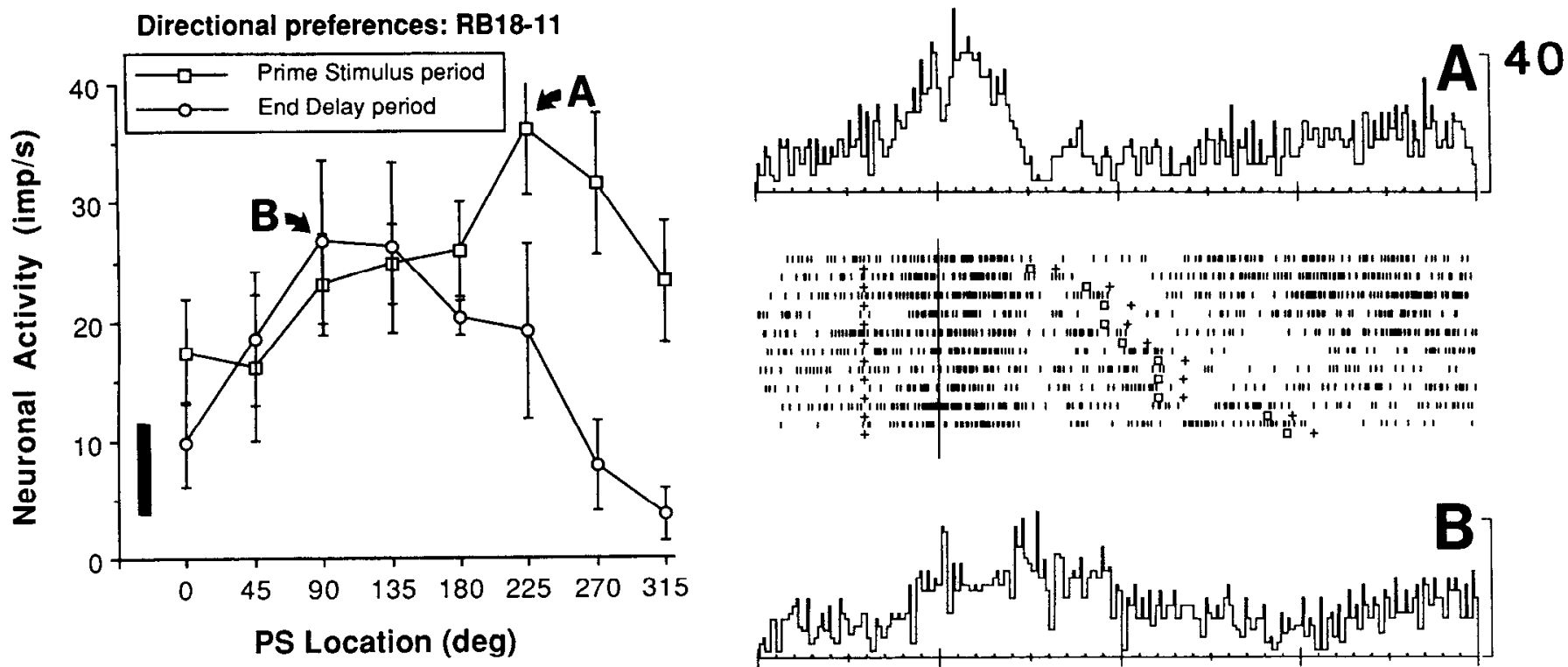

|

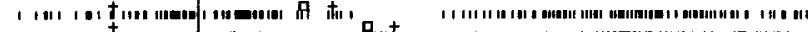

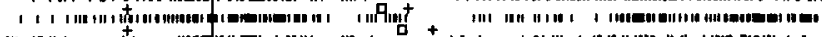

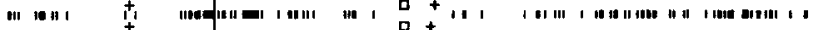

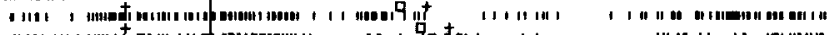

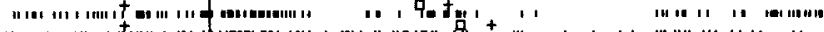

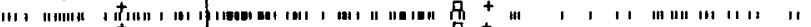

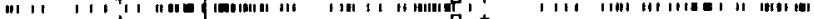

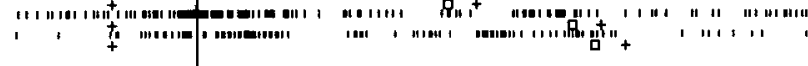
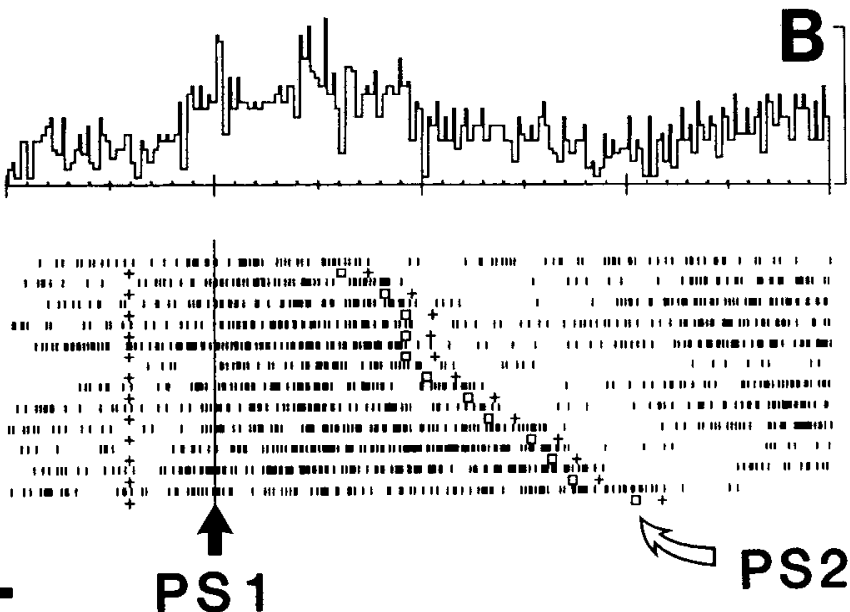

Figure 5. PM neuron showing different direction preference in two task periods. Each row of each raster display shows the activity during one trial; each tick, the time of the cell's discharge. The data are aligned on PS1, which is marked by the solid vertical line. The first plus sign beneath each row indicates the time of trial initiation; the second plus sign marks the onset of movement. Open squares indicate the time of PS2. The histogram shows average activity for each raster display; the scale is in impulses/second and is the same for the two histograms. $A$ and $B$, Rasters and histograms illustrate the points so labeled in the graph (upper left). The graph shows mean ( \pm SD) activity for each of the eight PS locations (as designated in Fig. 1) for the prime stimulus period (open squares) and the end of the delay period (open circles). On the graph, the thick, solid vertical bar shows the reference activity \pm SD. Time scale: major divisions, $2 \mathrm{sec}$; minor divisions, $200 \mathrm{msec}$. 


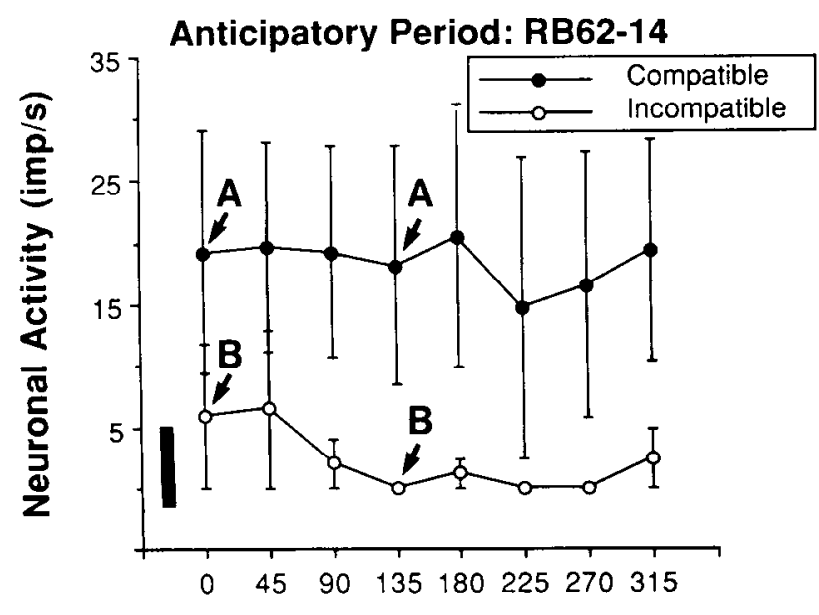

PS Location (deg)

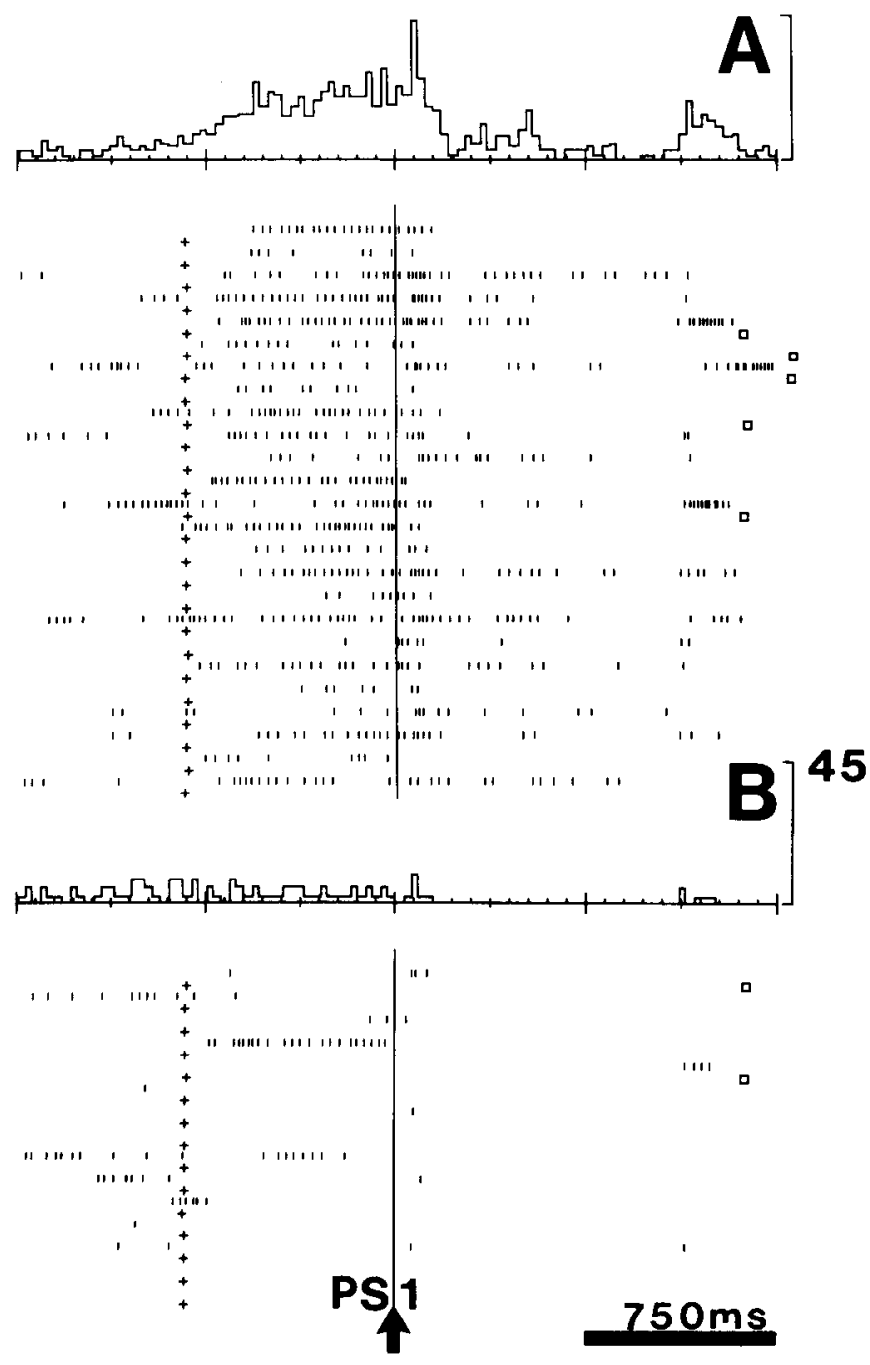

Figure 6. PM neuron with anticipatory activity. The graph at the top shows mean $( \pm S D)$ activity for each of the eight PS locations (as designated in Fig. 1) in both conditions. The solid, thick vertical bar shows \pm SD of the reference-period activity. Open squares indicate the time of PS2 in those trials when it occurred soon enough to appear within he display time window. Note that the points with no variance indicate

- all trials had 0 impulses/sec. The raster and histograms in $A$ and both of the points so labeled in the graph (arrows). curred in the movement period (not shown), as in all task-related muscles. Many cells showed significantly different activity in the two conditions. Figure 7, which shows the activity of a PM neuron, illustrates a dramatic condition effect. In the compatible condition, after the presentation of a PS1 stimulus down and to the left, the cell phasically discharged at about 80 impulses/ sec (Fig. 7A). (Note that the average activity plotted on the graph gives a lower average activity because a longer time window decreased the mean value.) However, when PS1 appears in other locations, the cell discharged less vigorously, showing virtually no poststimulus discharge after a stimulus up and to the right (Fig. $7 B$ ). A comparison of Figure $7, A$ and $B$, along with the poststimulus discharge for the other six PS1 locations, shows the directional selectivity expected in a task of this kind (Fig. 7 , top left, solid circles). However, in the incompatible condition, when PS1 appeared down and to the left (Fig. 7C), the same location as in Figure $7 A$, the cell showed only a weak discharge. Since that spatially and physically identical PS1 was attended to in both conditions, the difference between $A$ and $C$ and, more generally, the difference between the two curves can only result from the instructional significance of the events.

Other cells failed to show a significant condition effect. Figures 10 and 11 show two PF cells that lack condition effects in any task period. Condition effects were significantly more common in PM than in PF (Table 2). We measured the magnitude of each cell's condition effect by computing a condition effect index (see Materials and Methods). Table 2 gives the number of cells for which activity varies by a factor of 2 between conditions, and shows that PM had a greater number of such cells than did PF. In PM, most cells that show a condition effect were more active in the compatible condition. In PF, when there was a condition effect, the greatest activity occurred equally frequently in either condition.

In most instances, activity differed for all PS locations, taken as a group (main effects). In PM, $67 \%$ of instances $(82 \%$ of instances with significant condition effects) tested showed main effects of condition, while in PF, 35\% of instances $(71 \%$ of instances with significant condition effects) did so. Less often ( $15 \%$ of PM instances and 6\% in PF), the difference in condition was dependent on the position of the prime stimulus and pertained only to certain PS locations.

Cells could have different preferred direction in the two conditions (Fig. 12). For each task period, we calculated the absolute value of the difference in preferred directions for the compatible versus incompatible conditions. In $\mathrm{PM}$, that difference was $47^{\circ}$ $\pm 50^{\circ}(N=87)$ in the PS1 period, whereas after PS2 it was twice as much, $94^{\circ} \pm 53^{\circ}(N=79)$. These means were significantly different (two-tailed Wilcoxon test, $p<0.02$ ). Preferred direction differences for delay-period activity (for compatible vs incompatible conditions) were intermediate, $69^{\circ} \pm 56^{\circ}(N=82)$, and this mean significantly differed from both that after PS1 and that after PS2. By contrast, in PF the condition-dependent differences in preferred direction did not significantly differ by task period. They were as follows: $60^{\circ} \pm 48^{\circ}(N=44)$ for PS1 period activity, $47^{\circ} \pm 40^{\circ}(N=32)$ for delay-period activity,

Approximately half of the trials shown in $A$ were recorded after that shown in $B$, and about half before that shown in $B$. Histogram scale is in impulses/second and is the same for all histograms. Time scale: major divisions, $750 \mathrm{msec}$; minor divisions, $75 \mathrm{msec}$. 
Prime Stimulus period: RB63A-07
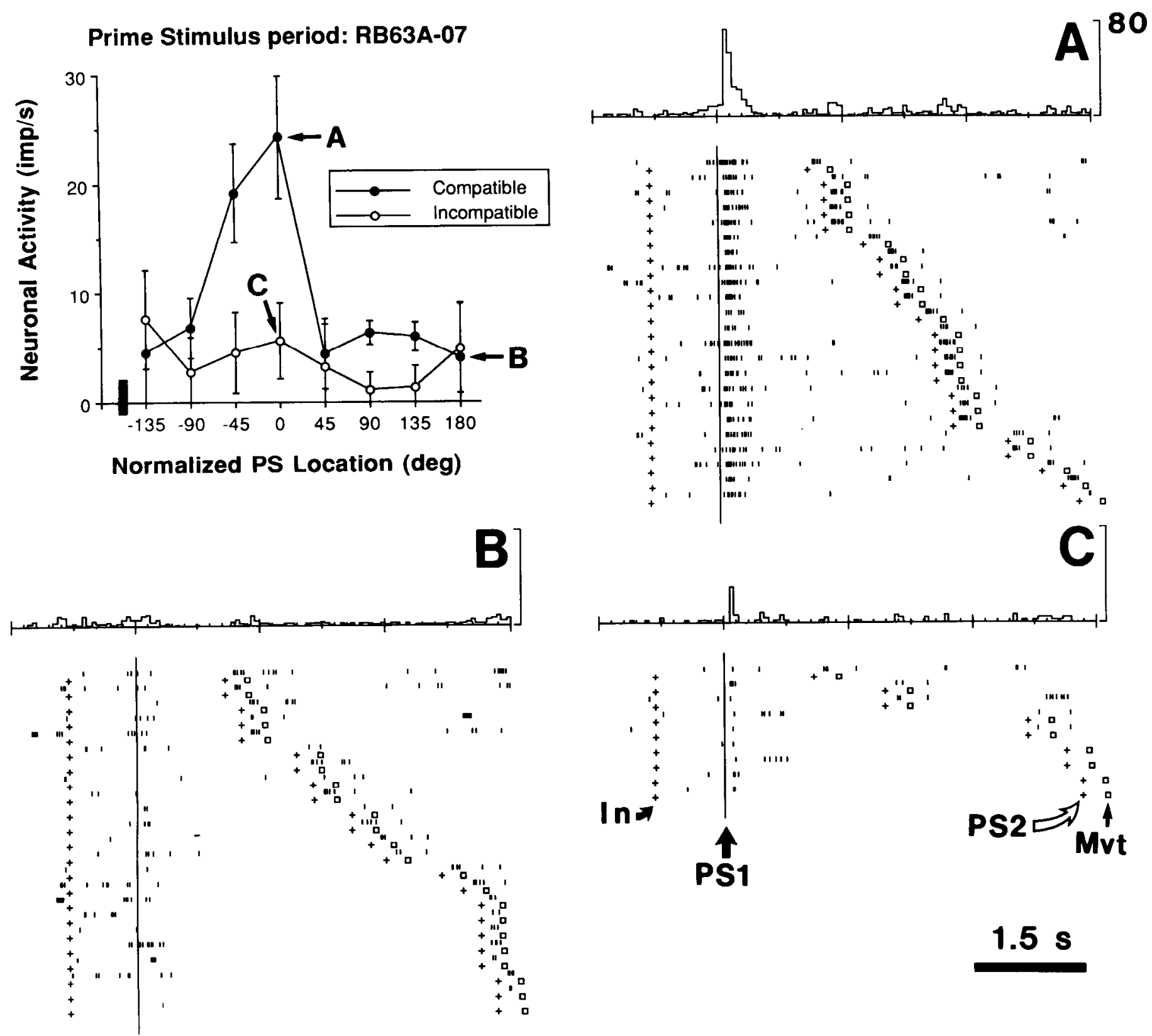

Figure 7. PM neuron with activity following the prime stimulus. PS locations are normalized to the preferred stimulus location $\left(0^{\circ}\right)$. For this cell, that was position $8\left(315^{\circ}\right)$ as shown in Figure 1. Format is as in Figure 6. As in Figure 6, the first plus sign for each trial shows the time of trial initiation (In), and the raster is aligned on PS1. In addition, the second plus sign on each line shows the time of PS2, and the open square indicates the onset of movement $(M v t)$. Raster and histogram displays labeled $A-C$ correspond to the data points so labeled in the graph. A comparison of $A$ and $B$ exemplifies the position effect, and a comparison of $A$ and $C$ demonstrates the maximal condition effect. Note that the cell responds briskly after each PS presentation (PS1 and PS2) in $A$, but weakly, if at all, in $B$ and $C$. Histogram scale is in impulses/second and is the same for all histograms. Time scale: major divisions, $1.5 \mathrm{sec}$; minor divisions, $150 \mathrm{msec}$.

and $51^{\circ} \pm 49^{\circ}(N=39)$ for post-PS2 discharge. Examining the cells with directional selectivity in both conditions, we could class their condition effects into three categories, at least for PM: (1) those that had dramatically $\left(>90^{\circ}\right)$ different preferrcd dircction in the two conditions (13\% PS1 period, 35\% delay period, $48 \%$ premovement period); (2) those with similar preferred directions ( $<45^{\circ}$ different), but a different modulation of "tuning" (66\% PS1 period, $54 \%$ delay period, $22 \%$ premovement period); and (3) those that were intermediate (the remainder). Thus, early in a trial, that is, nearer the time of PS1, the directional pref- erences in the two conditions were more similar than later, that is, nearer the movement (see Crammond and Kalaska, 1990). The number of PF cells with a condition effect was insufficient to perform a similar analysis.

Position effects. The position effect was studied separately for the incompatible condition because in that condition stimuli at eight different locations triggered the same movement. Figure 13 illustrates the position effect for a PM cell active during the delay period (see also Figs. 10-12). This cell had little or no task-related activity during the compatible condition (not shown). 

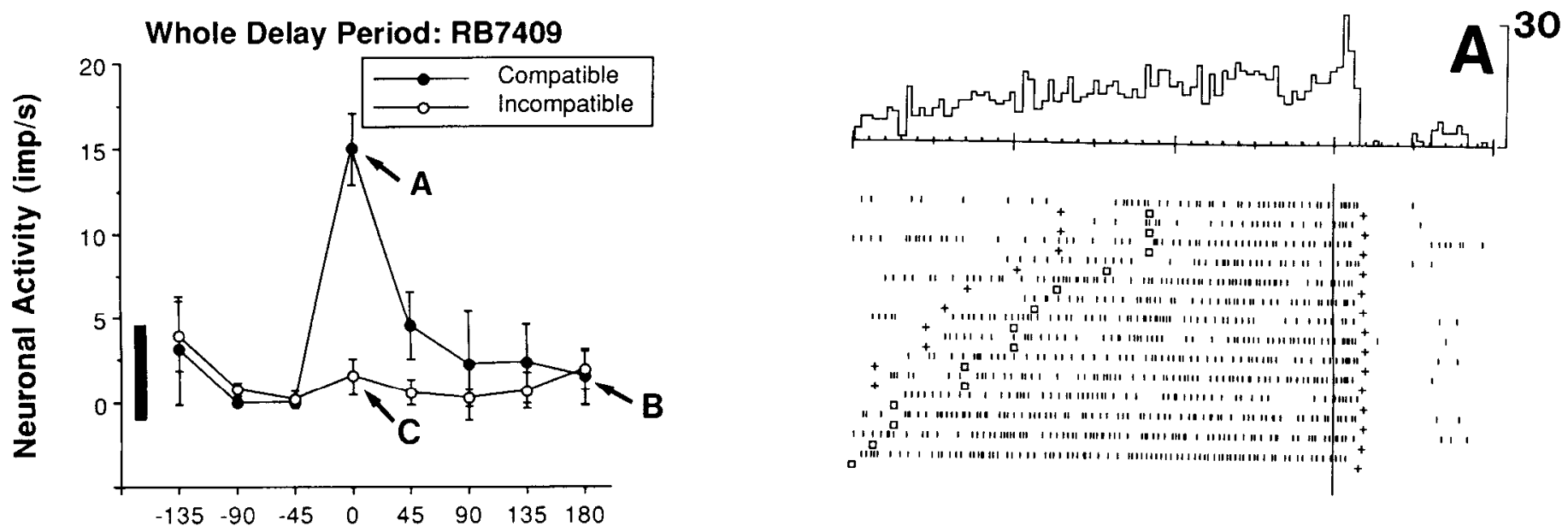

Normalized PS Location (deg)
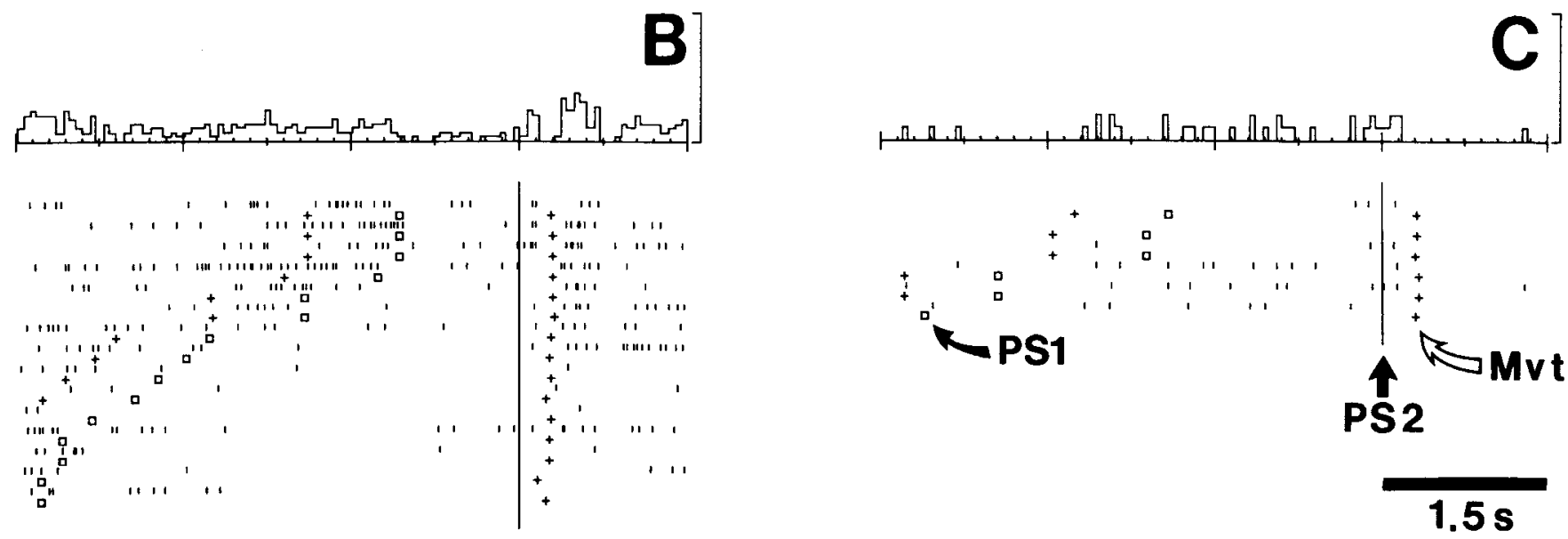

Figure 8. PM cell showing a condition effect on delay-period activity. Format is as in Figure 7, except that the rasters are aligned on PS2 and squares mark PS1. The left plus sign on each raster line, when present, marks trial initiation; the next plus sign shows movement onset time (Mvt). The preferred PS location was position $2\left(45^{\circ}\right)$. Histogram scale is in impulses/second and is the same for all histograms. Time scale: major divisions, $1.5 \mathrm{sec} ;$ minor divisions, 150 msec.

Table 3 shows the number of cells that showed a significant effect of PS position in the incompatible condition $(p<0.05$, two-factor ANOVA).

We specifically compared the activity before movements in response to prime stimuli at location 5 . This was the position that was the repetitive target of all limb movements in the incompatible condition, and therefore the stimuli and movement were both the same when PS1 appeared at position 5 . Although not all cells with condition effects could be tested, in those instances that were, we only rarely ( 7 of $169,4 \%$ in PM; 1 of $51,2 \%$ in PF) observed a significant difference between conditions when the prime stimulus appeared at location $5 \mathrm{CH}$ key post-hoc comparison, $\alpha=0.05$ ), excluding the anticipatory period in PM, where 9 of $39(23 \%)$ showed such a difference before PSI onset. For example, the points at normalized PS locations $-135^{\circ}$ in Figure $7,+135^{\circ}$ in Figure 8 , and $180^{\circ}$ in Figure 12 were at PS location 5.

\section{Histology}

Figure 14 shows the location of cells with condition effects. All of the cells designated as being within PM were located within area 6 as defined cytoarchitectonically (see Brodmann, 1905,
1909; Weinrich and Wise, 1982; Wise, 1984, 1985; Barbas and Pandya, 1987). PF cells were in areas 12 and 46 according to surface landmarks (see Walker, 1940; Barbas and Pandya, 1989) or area 9 according to Brodmann (1905, 1909).

For the prime stimulus period, the PM cells lacking a condition effect were mostly located in the rostral part of the dorsal premotor area (Fig. 14). With this exception, the distribution of cells with condition or position effects within either PM or $P F$ was not noteworthy. Figures 15 and 16 show the histological reconstruction for the penetrations in which task-related neurons were observed, for PF and PM, respectively.

\section{Discussion}

A major focus of the behavioral neurophysiology of the frontal cortex has been an attempt to interpret neuronal activity in either sensory or motor terms (Rizzolatti et al., 1981, 1987, 1988; Seal and Commenges, 1985; Funahashi et al., 1989, 1990, 1991; Alexander and Crutcher, 1990a,b; Crammond and Kalaska, 1990, 1991; Burbaud et al., 1991; Riehle, 1991; Kalaska and Crammond, 1992). Especially in the more caudal parts of the frontal cortex, the emphasis has been on motor interpretations (Godschalk et al., 1981, 1985; Weinrich and Wise, 1982; 


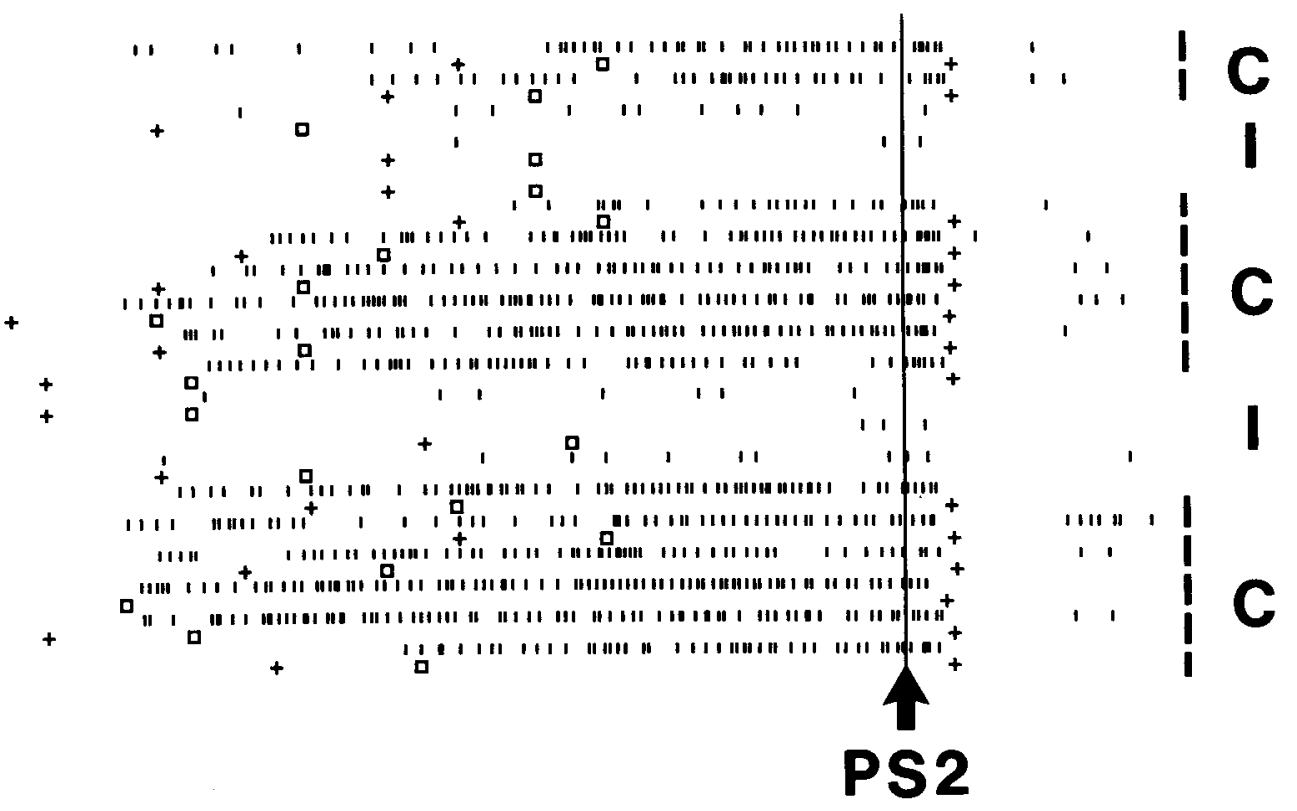

Figure 9. Repeatability of condition effect in same cell as shown in Figure 8 . Trials for the preferred PS location are displayed in the order presented from top to bottom. Trials marked with $C$ (right column) and the vertical broken line are from the compatible condition; those marked with an $I$ are from the incompatible condition. Time window is the same as in Figure 8.

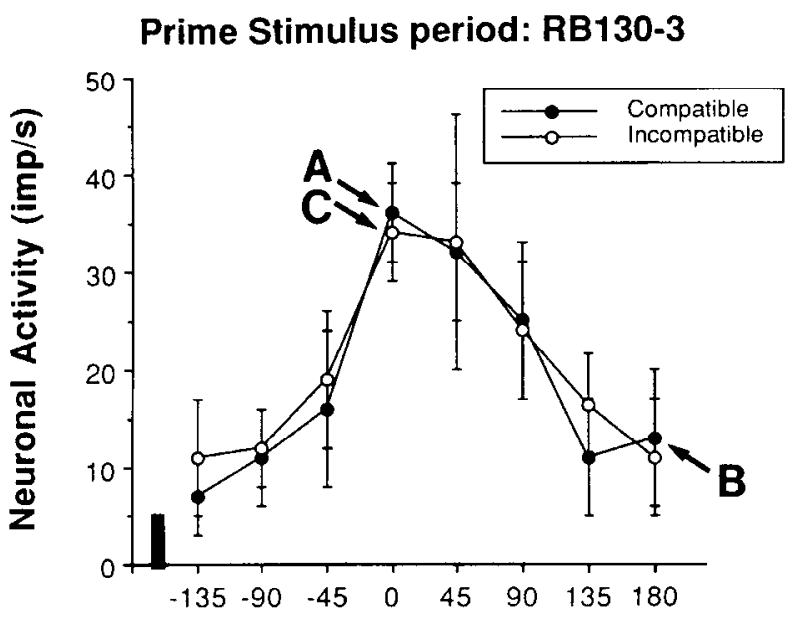

Normalized PS Location (deg)

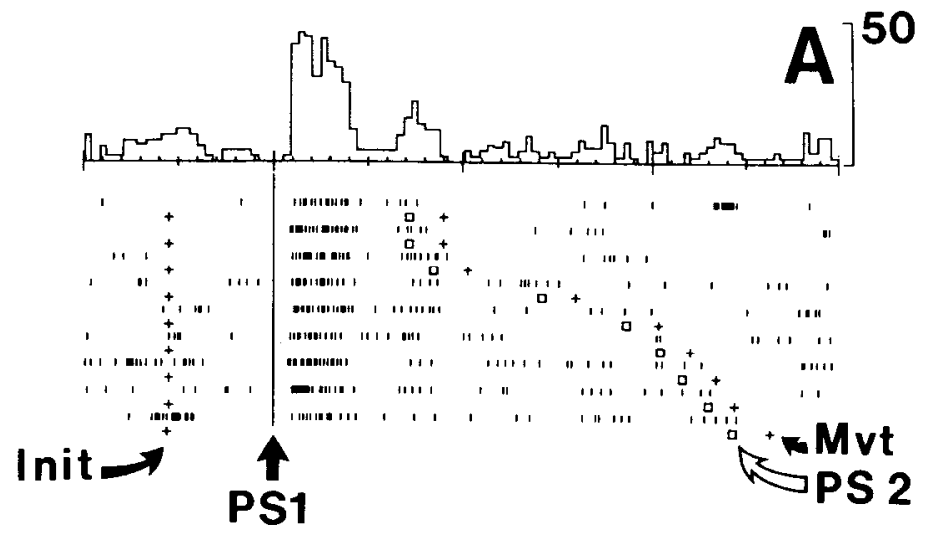

$2 s$
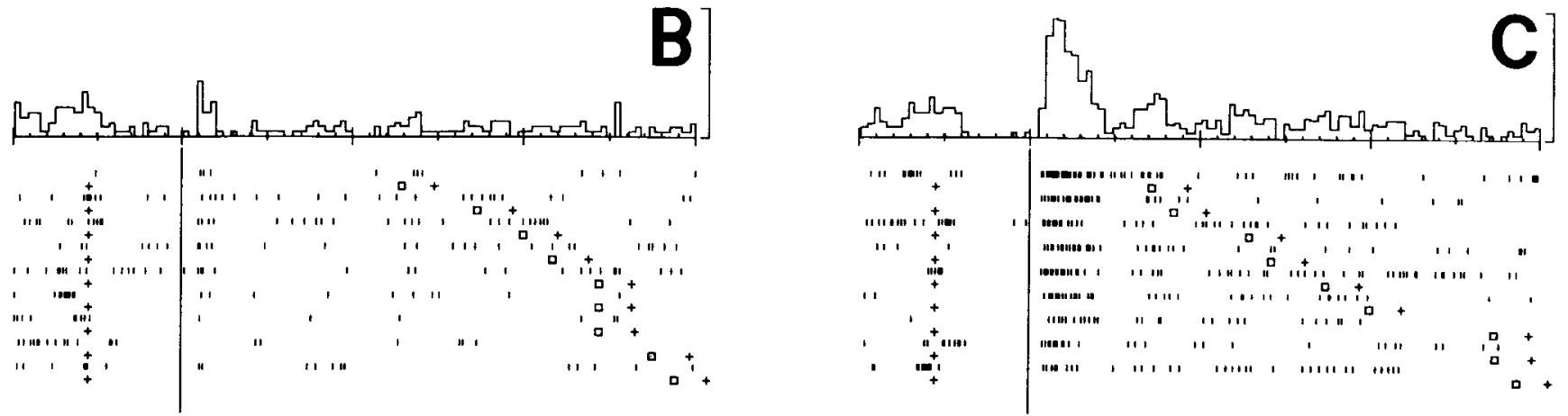

Figure 10. PF cell showing no condition effect in prime stimulus period. Format is as in Figure 7, except that the square marks PS2 onset and the right plus sign indicates the onset of movement $(M v t)$. Preferred PS location is position $2\left(45^{\circ}\right)$. Histogram scale is in impulses/second and is the same for all histograms. Time scale: major divisions, $1 \mathrm{sec}$; minor divisions, $100 \mathrm{msec}$. 
$\stackrel{\circ}{\circ}$
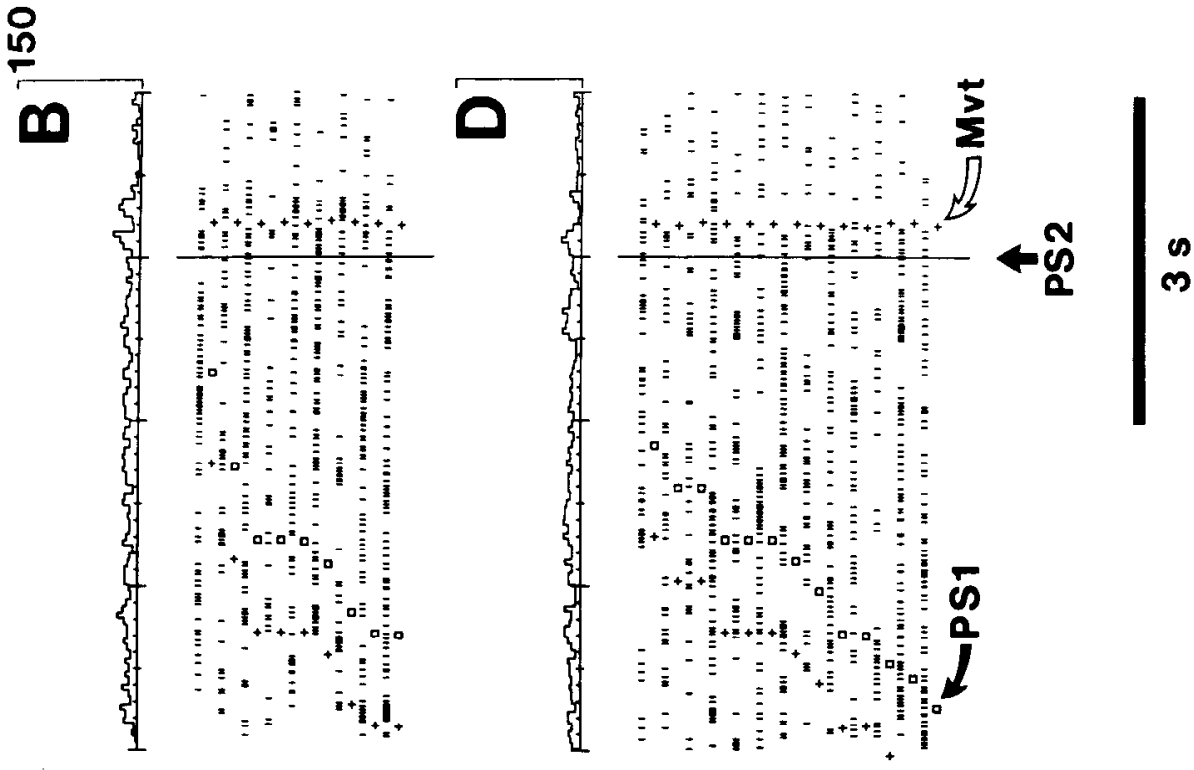

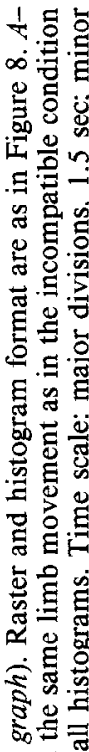

홍.

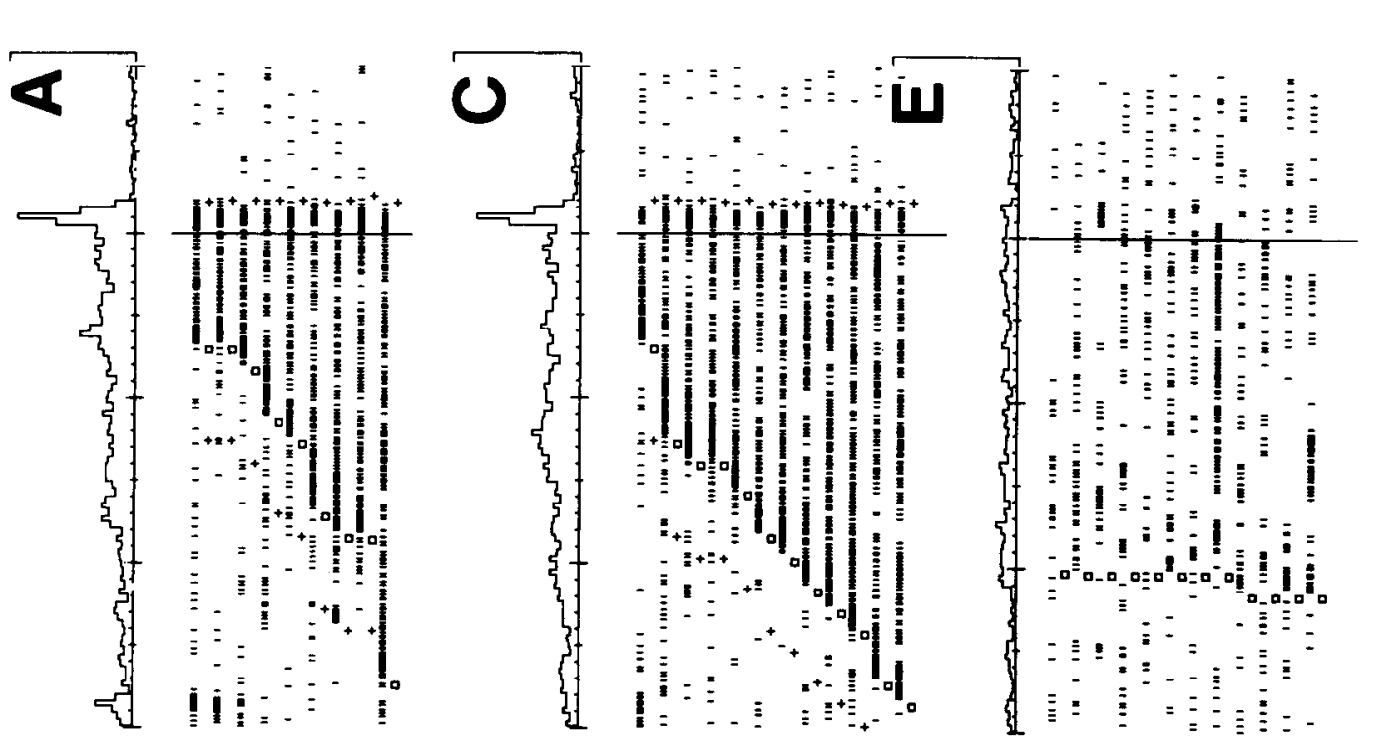

政
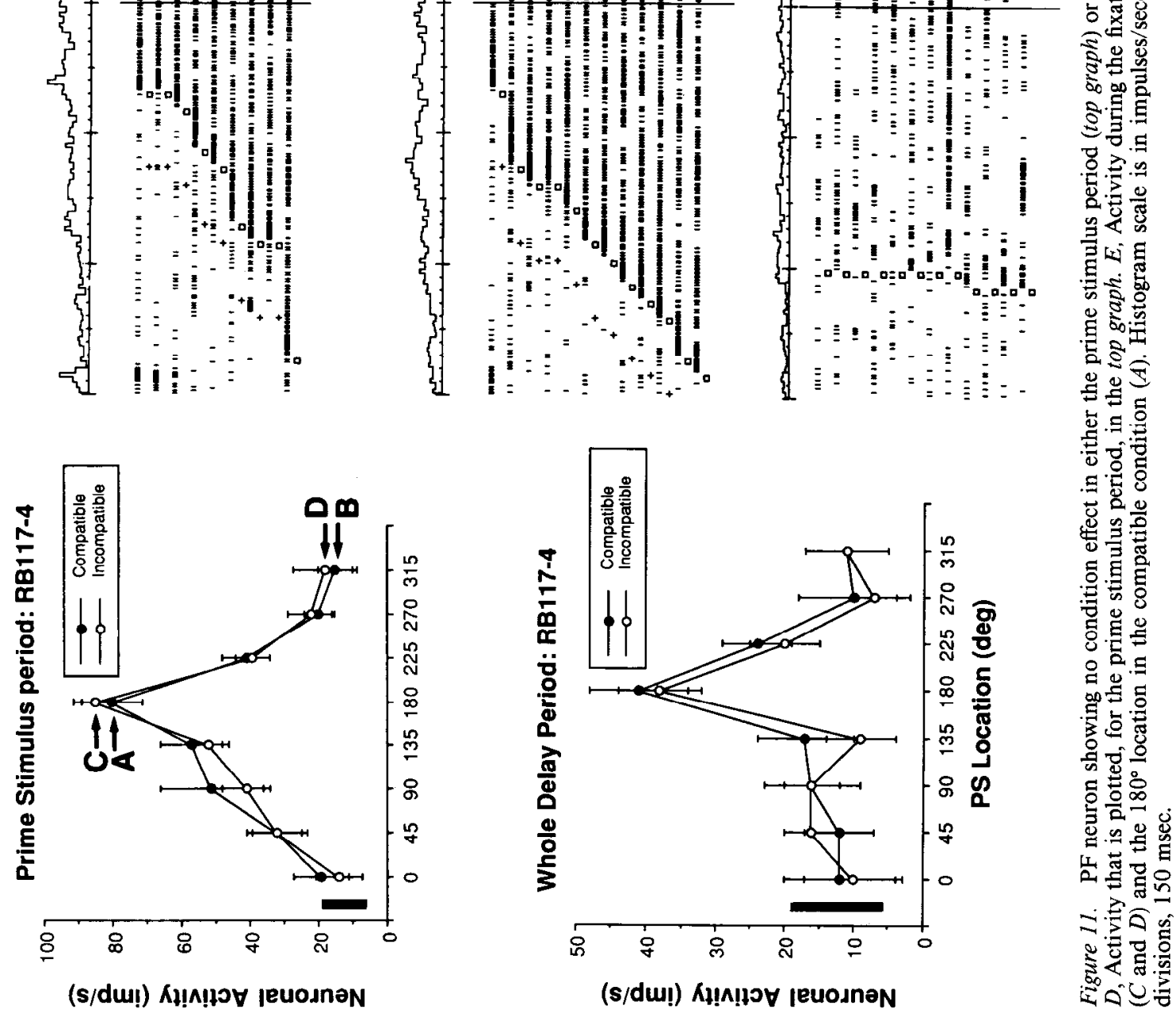

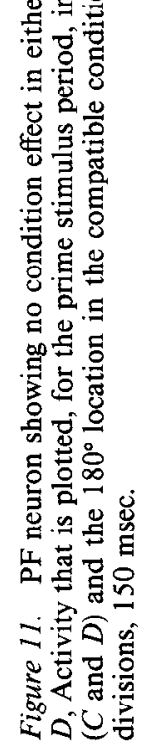



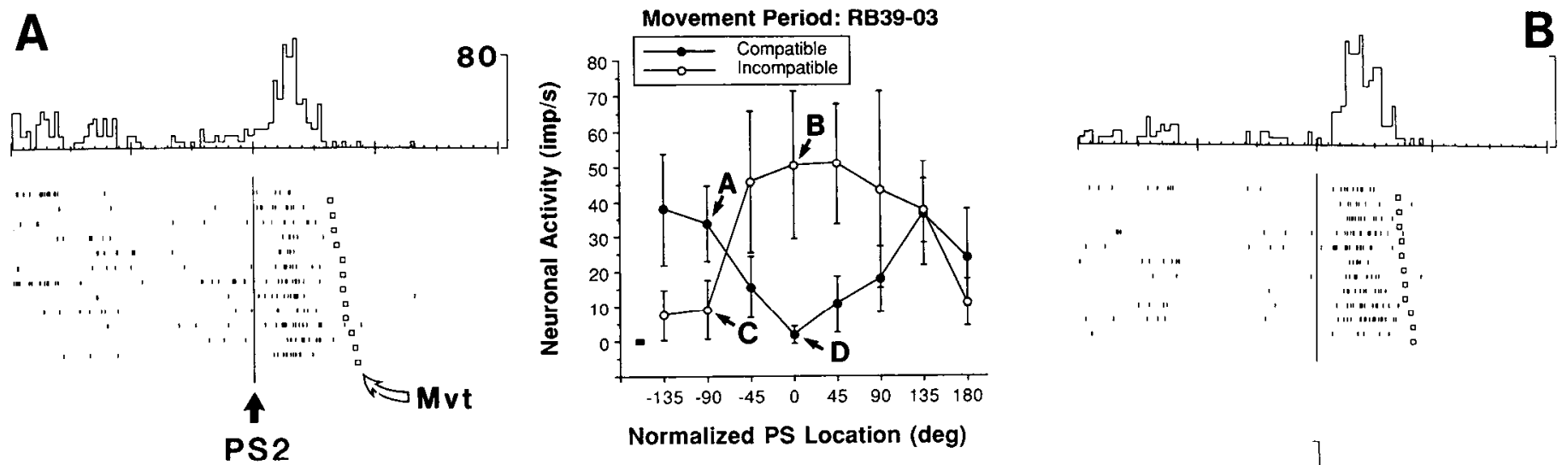

$0.4 \mathrm{~s}$
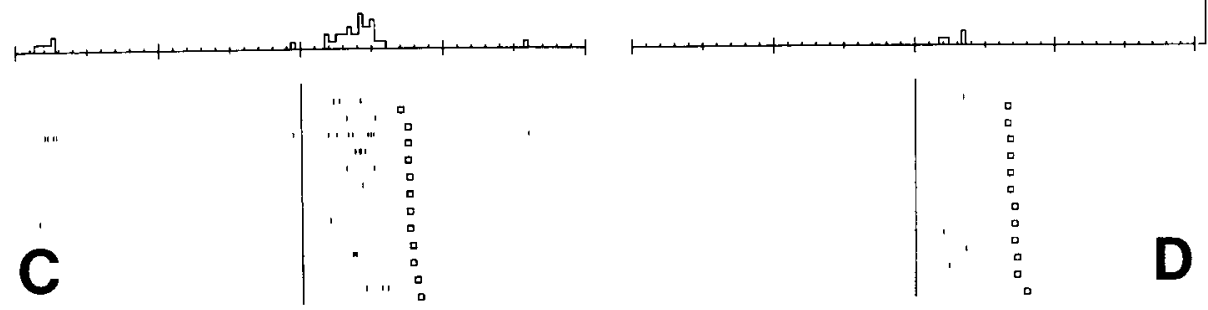

Figure 12. PM cell during movement period. Note that the preferred direction differs in the two conditions. The graph is normalized to the preferred PS location in the incompatible condition, which was position $1\left(0^{\circ}\right)$. Histogram scale is in impulses/second and is the same for all histograms. Time scale: major divisions, $400 \mathrm{msec}$; minor divisions, $40 \mathrm{msec}$.

Wise and Mauritz, 1985; Kurata and Tanji, 1986; Okano and Tanji, 1987; Rizzolatti et al., 1987, 1988; Kurata and Wise, 1988b; Riehle and Requin, 1989; but cf. Lurito et al., 1991), though there have been exceptions (Kwan et al., 1981, 1985; Rizzolatti et al., 1981; Wannier et al., 1989; Riehle, 1991). In more rostral areas, discussion has focused on sensory and perceptual functions, especially spatial localization, and storage of such information (Kubota and Niki, 1971; Fuster, 1973; Kubota et al., 1974; Niki, 1974a-c; Niki and Watanabe, 1976; Kojima, 1980; Mikami et al., 1982; Vaadia et al., 1986; Watanabe, 1986a,b, 1989, 1990; Bakay Pragay et al., 1987; Joseph and Barone, 1987; Yajeya et al., 1988; Barone and Joseph, 1989; Boch and Goldberg, 1989; Funahashi et al., 1989, 1990, 1991), despite the fact that a large number of cells discharge just before movement (Kubota and Niki, 1971; Fuster, 1973; Niki, 1974a; Kubota and Funahashi, 1982; Funahashi et al., 1991). Despite these disparate interpretations of the neurophysiological data, rarely have PM and PF been compared in a single animal. Different experimental designs, species, laboratories, and cortical regions have been involved in past work. Indeed, there are only a few, limited studics that explicitly compare the activity in a motor area and a prefrontal area (Kubota and Funahashi, 1982; Vaadia et al., 1986; Watanabe, 1986a,b, 1990; di Pellegrino and Wise, 1991a; see also Sakai, 1978; Bakay Pragay et al., 1987).

The present study provides such a comparison of PF and PM in a single animal. The present behavioral design, a spatial matching-to-sample task, established the control necessary to identify motor (instructional) influences on neuronal activity. In both the compatible and the incompatible condition, the monkey had to attend to or remember the spatial location of the salient stimuli, which differed (by condition) only in their instructional significance. The task accomplished this objective as follows: (1) head and gaze angle fixation established that the prime stimuli occurred at the same retinocentric, craniocentric, and external (allocentric) coordinates regardless of condition; (2) the PS location had to be attended to or remembered during the delay period in both conditions because the reappearance of a stimulus at that location triggered a reaction-time movcment in both conditions: (a) the wide variation in delay periods $(0.95-4.65 \mathrm{sec})$, coupled with a relatively short reaction and movement time limit $(0.65 \mathrm{sec})$, precluded a timing strategy (waiting a certain amount of time before executing the movement); and (b) the unpredictable number (0-4) of otherwise irrelevant distractor events prevented a counting strategy (executing a movement on the $n$th event). With this degree of behavioral control, we were able to establish that the motor significance of visuospatial instructional stimuli affects neuronal discharge much more commonly in PM than in PF.

\section{Interpretational limitations}

There were two ways to perform the present task. One might be called an attentional strategy, the other a mnemonic strategy. That is, the monkey could successfully perform the task either by remembering the PS location (and initiating a response upon the second presentation of that stimulus) or by shifting spatial attention to the PS location (and initiating a response when a stimulus appears at the attended location). The present task could not dissociate those two possibilities. Perhaps there are some clues, however, in the reaction-time data. There was a clear effect of stimulus-response compatibility on reaction time (Table 1). Reaction times were faster when stimulus and response corresponded in space (compatible mapping) than when they did not correspond (incompatible mapping). In addition, there was a systematic increase in reaction time in the incompatible condition as the PS location diverged from the repetitive movement direction (Table 1; see Georgopoulos and Massey, 1987). These observations are consistent with a systematic shift 
End Delay Period: RB3904

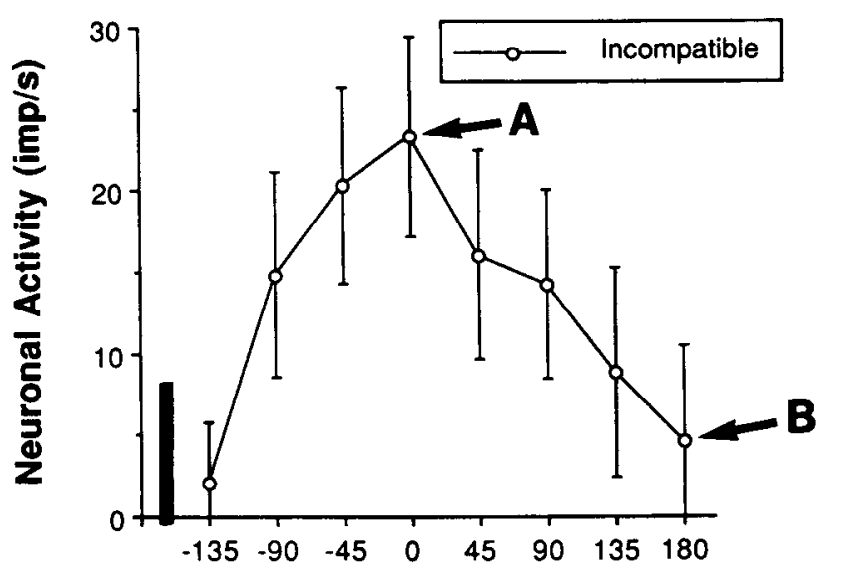

Normalized PS Location (deg)

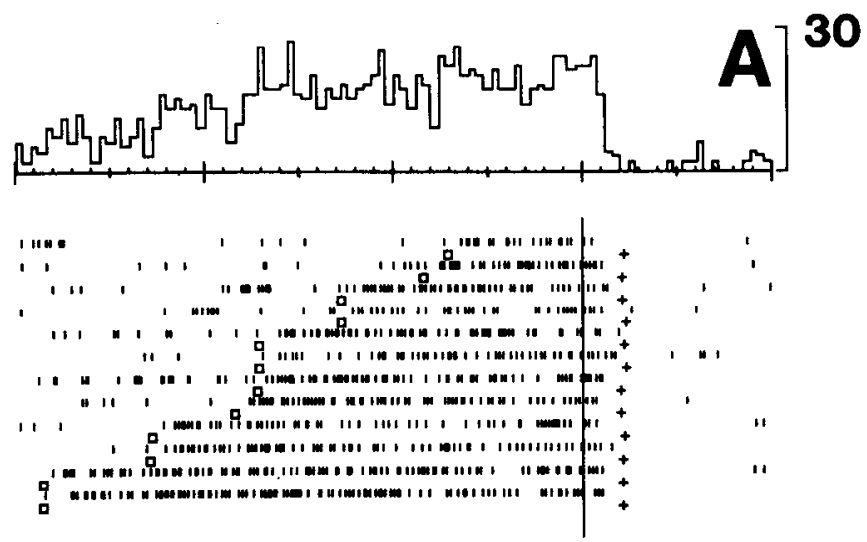

B
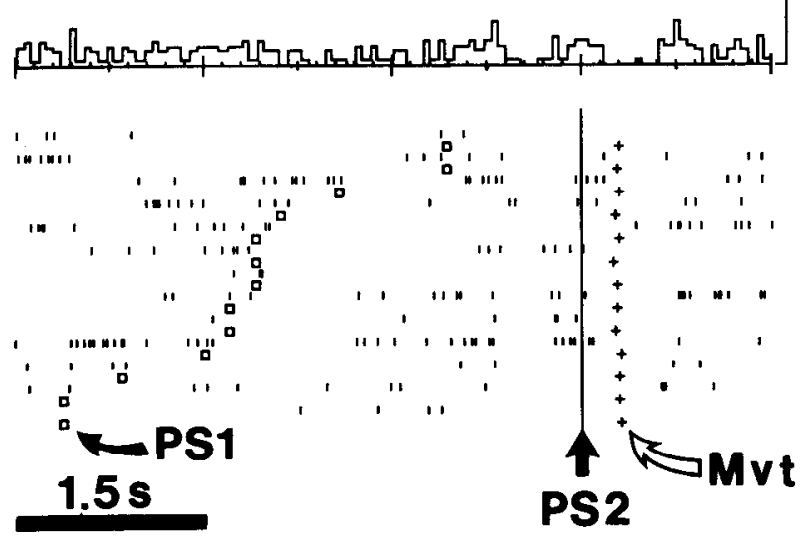

Figure 13. PM cell showing a position effect in the incompatible condition. Delay-period activity is shown in the format of Figure 8. Histogram scale the same for all displays. Preferred direction is PS location $8\left(315^{\circ}\right)$. Histogram scale is in impulses/second and is the same for all histograms. Time scale: major divisions, $1.5 \mathrm{sec}$; minor divisions, 150 msec.

of spatial attention, weakly supporting the view that the monkey adopted an attentional strategy.

We also emphasize that the present experimental design does not entail the comparison of activity following multiple stimuli
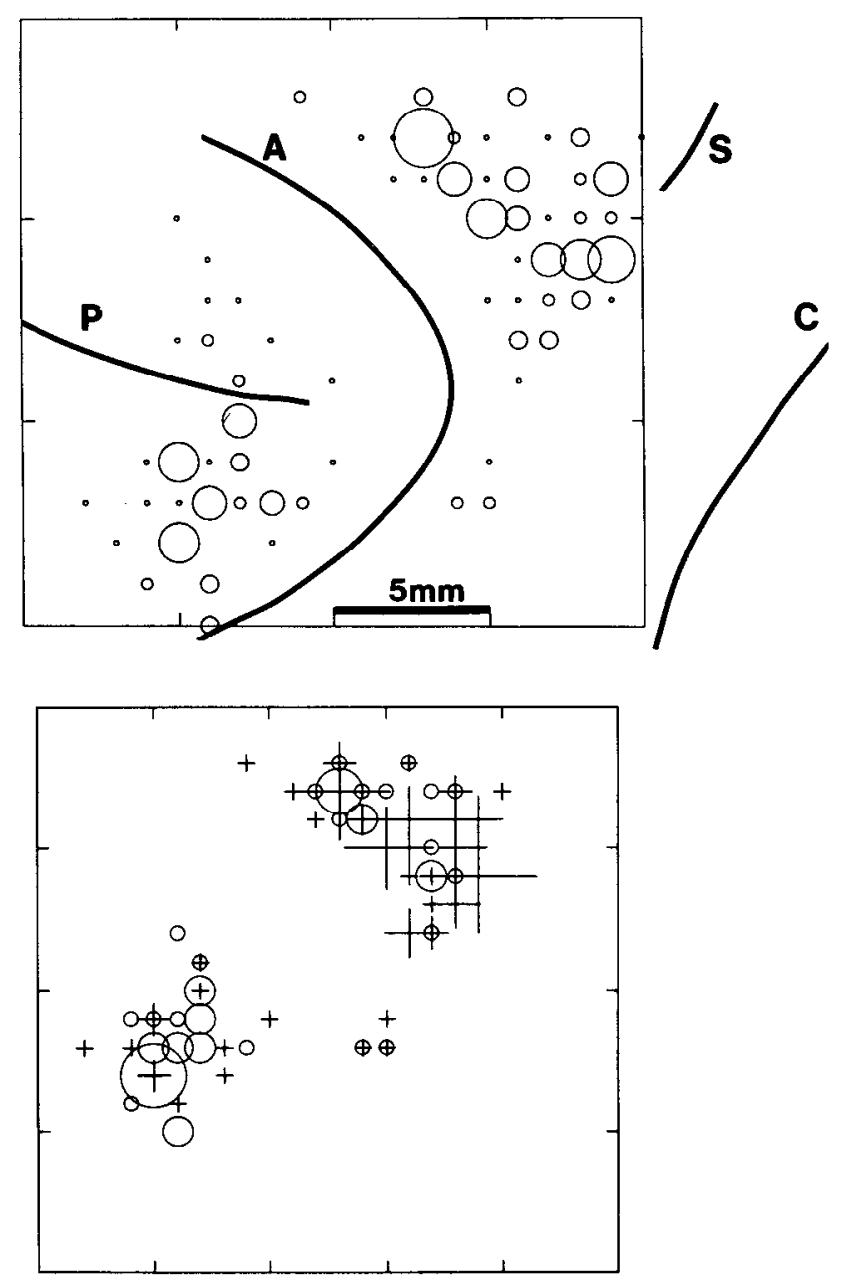

Figure 14. Top, Distribution of task-related neurons. The diameter of each circle is proportional to the number of cells recorded at that location (with the smallest circles indicating one cell, and the largest circles, nine cells). $A$, arcuate sulcus; $C$, central sulcus; $P$, principal sulcus; $S$, superior precentral sulcus. Caudal is to the right, lateral to the bottom. Bottom, Distribution of cells showing (plus signs) and lacking (circles) condition effects in the prime stimulus period, plotted into the same coordinates. The size of each symbol is proportional to the number of cells at that location with the indicated property. Note that, within PM, the circles appear to be concentrated rostrally.

that instruct a fixed response. At first glance, the incompatible condition appears to allow just such a comparison: after stimuli at any of eight locations, the monkey executes a single response. However, the stimuli in the incompatible condition are never instructions; they only trigger a movement that must be selected on the basis of recent reward history.

It is essential to inquire as to whether the observations can be simply explained on the basis of muscle activity or some aspect of oculomotor behavior. Two muscles, infraspinatus and extensor carpi radialis, showed activity during the anticipatory, prime stimulus, and early delay period. One of these muscles, extensor carpi radialis, showed activity throughout the delay period on most trials. The patterns of EMG activity during these pertinent task periods did not resemble those of the neurons in either PM or PF. EMG activity during the anticipatory period, extension sometimes into the prime stimulus period, showed a steady decrement from the time of the return movement and appears to be a continuation of EMG activity begun during the 
Table 3. Effect of position in the incompatible condition (two-factor ANOVA, $\alpha=0.05$ )

\begin{tabular}{lccl} 
Task period & PM & PF & $\chi^{2}$ test \\
\hline Anticipatory & $8 / 63(13 \%)$ & $1 / 37(3 \%)$ & $\chi^{2}=2.8, p=0.09$ \\
Prime stimuli & $49 / 70(70 \%)$ & $26 / 39(67 \%)$ & $\chi^{2}=0.1, p=0.7$ \\
Whole delay & $66 / 83(80 \%)^{* * *}$ & $15 / 33(45 \%)$ & $\chi^{2}=13.0, p=0.0003$ \\
End delay & $56 / 76(74 \%)^{* * *}$ & $12 / 36(33 \%)$ & $\chi^{2}=16.7, p=0.0001$ \\
Movement & $47 / 77(61 \%)^{*}$ & $19 / 45(42 \%)$ & $\chi^{2}=4.0, p=0.04$ \\
\hline
\end{tabular}

Format and inclusion criterion are as in Table 2.

previous movement and its return. Neurons rarely showed this pattern of activity. Instead, neurons with anticipatory activity typically increased dramatically during the period leading up to the prime stimulus, in agreement with previous reports (Mauritz and Wise, 1986; Vaadia et al., 1988). For the prime stimulus period, there was an additional difference between EMG and neuronal activity. The EMG activity never shows directional selectivity during the prime stimulus period of the incompatible condition, in contrast to most neurons in both PM and PF. There is no muscle that is, like many neurons, virtually inactive in one condition but highly active in the other. Eye movements cannot account for either the condition or position effects since they were virtually identical for the two conditions and for each PS location.

A possible sampling bias in our search strategy must also bc considered. To overcome this problem, we routinely switched between conditions, especially if activity in a track was low.

\section{Test of hypotheses}

The experimental design allowed us to test two hypotheses. First, because (1) the visuospatial spatial stimuli were physically and spatially identical in the two conditions and (2) the monkey had to attend to or remember the location of the prime stimulus in the same manner, the behavioral design allowed us to test the hypothesis that task-related activity reflects simply reflects the sensory aspects of the stimulus. Alternatively, the motor instructional significance of the stimuli could affect cell activity. Second, because, in the incompatible condition, a single motor response followed a variety of visuospatial cues, we could test the hypothesis that task-related activity reflected simply the animal's motor behavior, without any influence of the sensory signals that trigger that behavior. Alternatively, some aspect of the visuospatial cue, attention, or sensory information processing could affect cell activity. For most PM neurons, both hypotheses can be rejected, a conclusion resembling that of Lurito et al. (1991) for primary motor cortex. For PF ncurons, the sensory hypothesis can be rejected significantly less frequently than for those in PM.

Sensory hypothesis. For PM, we were able to reject the hypothesis that the activity immediately after PS onset could be accounted for solely in sensory terms. This conclusion follows from the condition effect (Table 2): stimuli occurred in the same

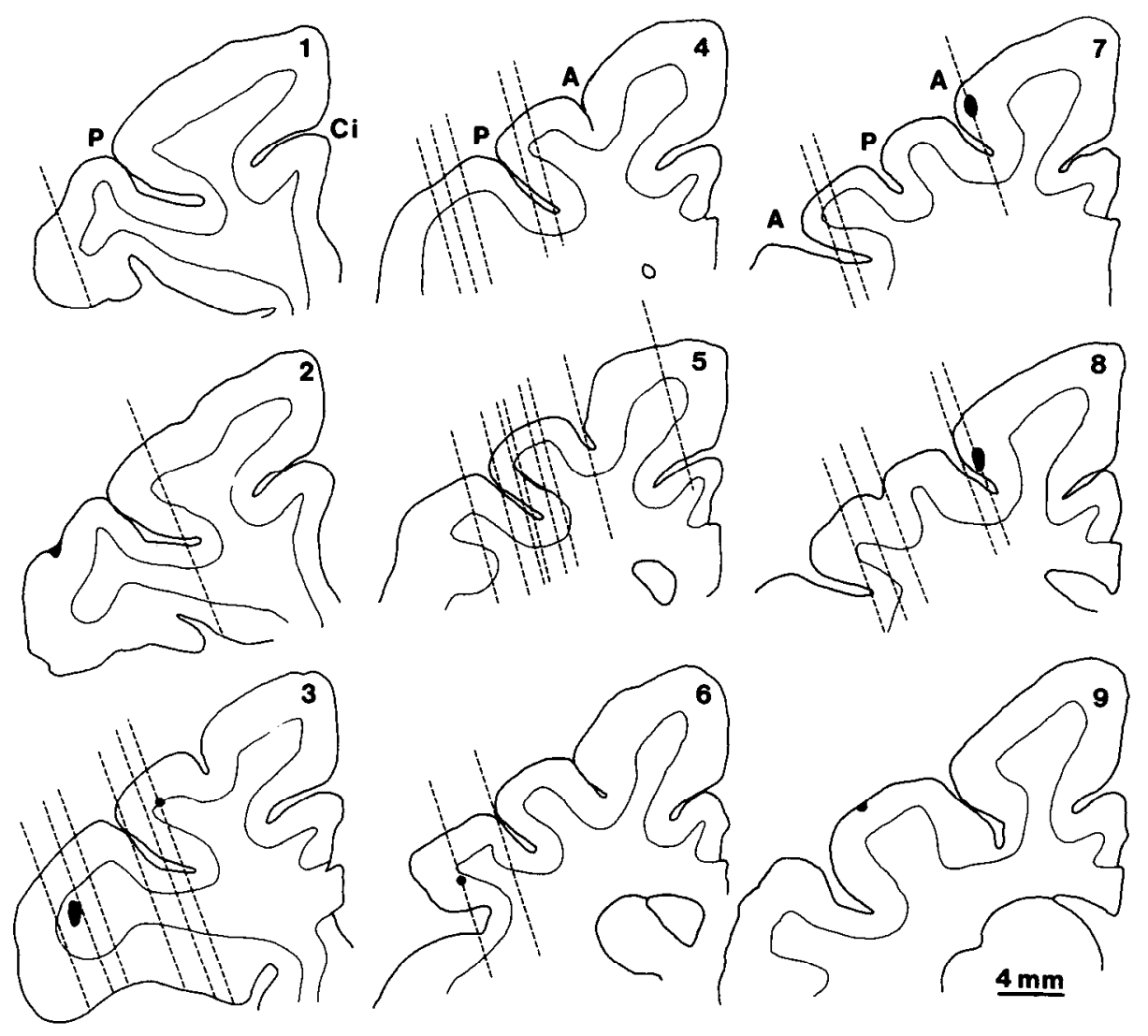

Figure 15. Histological reconstruction for PF. The broken lines show the penetrations in which task-related neurons were found. $C i$, cingulate sulcus. Solid circles show recovered lesion sites. 
Figure 16. Histological reconstruction for PM. Format is as in Figure 15. Solid circles show recovered lesion sites.
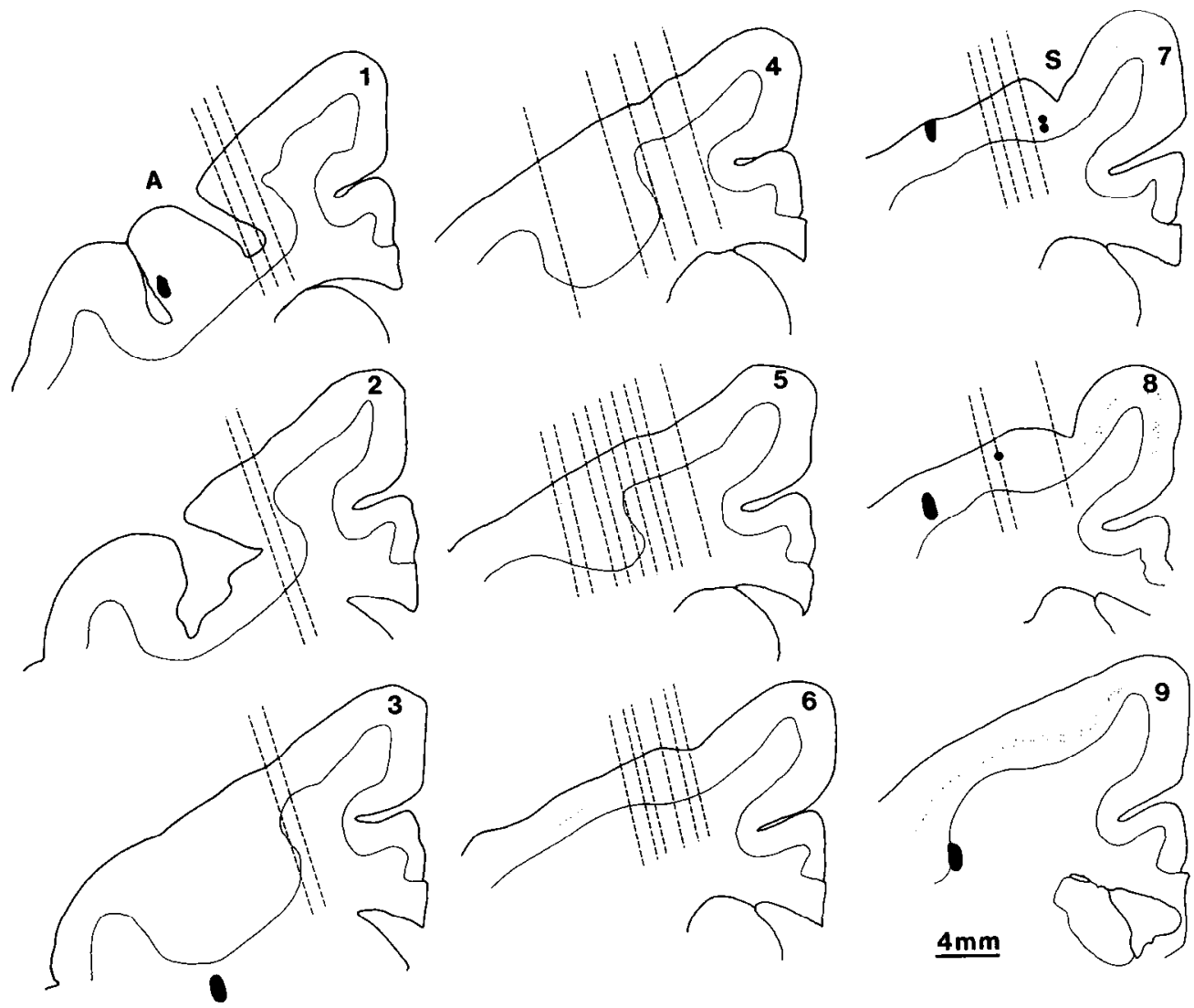

retinal coordinates and were attended to (or remembered) in the same manner, but had significantly and often dramatically different activity. Our conclusion differs from that of Riehle (1991), who based her conclusion on the "lime-locking" or temporal correlation of poststimulus activity with the onset of the stimulus. The present finding shows that such an approach and related ones (see also Seal et al., 1983; Seal and Commenges, 1985; Requin et al., 1988; Burbaud et al., 1991; Okano, 1992), although attractive, cannot adequately distinguish sensory and motor-related activity in the CNS.

For PF, only approximately one-third of our sample showed condition-dependent activity differences. For that third of the population, the motor significance of sensory stimuli influences activity there, as it does in the majority of PM cells. Since rejection of the "sensory" hypothesis was relatively rare in PF, our findings might suggest that this area's activity reflects sensory, perhaps spatial, information processing. However, since this suggestion relies on negative findings, that is, the lack of significant condition effects, other interpretations remain possible. In general, the similarity in activity could reflect any aspect common to the two conditions, among which are attention, motivational factors, arousal, reward expectation, and others. We can argue against interpretations based on motivation, arousal, and reward expectation on the grounds that the activity of most cells were directionally selective in the incompatible condition, when those general factors were unlikely to differ according to the direction of movement. However, interpretations based on attention, especially spatial attention, must have equal standing with those based strictly on sensory information processing. The present experimental design does not allow us to draw any conclusions about which factor is most important in the cells lacking condition effects.

Vaadia et al. (1986) conducted a study much like the present one. They found cells (see their Figs. 6, 7) that were specific to a "localize" condition (similar to our compatible condition) versus a "detect" condition (which involved repetitive movements to the same target like our incompatible condition). In their task, there were two major differences between the conditions, whereas in our task there was only one. First, in neither their detect condition nor our incompatible condition did the monkeys need to use sensory information presented on a given trial to select a limb-movement target. Second, in their task, the monkey did not have to remember or attend to the location of the stimulus in the "detect" condition. The monkey could simply move to the repetitious target whenever the cue was detected, regardless of its location. However, in our incompatible condition, attentional and mnemonic factors were controlled. Despite this distinction in experimental design, our result closely follows theirs. Vaadia et al. compared the proportion of neurons modulated in relation to their "localize" and "detect" conditions, which roughly corresponds to our condition effect. In accord with the observations of Vaadia et al. (1986), we found that the PM population (their postarcuate sample) was more influenced by condition than the PF population (their prearcuate sample) by a factor of 2 or 3 to 1 (see also Watanabe, 1992, for ventral premotor area).

The present result also concurs with that of Niki and Watanabe (1976) for PF, who, reporting only delay-period activity, found that $68 \%$ of the delay-period PF cells with directional selectivity appropriate for testing had activity that reflected cue 
location rather than limb-movement direction. (Some of the cells they reported had directional selectivity that was inappropriate for testing in their experimental design, and we have eliminated those from our calculation.) Similarly, Funahashi and Goldman-Rakic (1990), also reporting only on delay-period activity, found that $68 \%$ of delay-period cells in PF had activity that differed according to the location of the instructing stimulus, rather than the saccade direction. In our PF sample, $62 \%$ of the delay-period cells failed to show a condition effect; that is, their activity appeared to correspond to the stimuli (or related factors) rather than to the two different movements they triggered.

Motor hypothesis. It is also of interest that we were able, for most PM neurons, to reject the hypothesis that activity during the delay period and immediately before movement simply reflects the upcoming movement. This conclusion follows from the significant position effect in the incompatible condition (Tablc 3 ), in which a single movement could be triggered by a variety of visuospatial signals. The activity of these cells is thus neither strictly sensory nor simply motor in nature. Although it is clear that the motor significance of the sensory signals affects the neuron's activity, other factors, such as attention and/or sensory information processing, also have an influence. We speculate that these neurons do not reflect simply the spatial position of the stimulus or the response direction, but the relation or association between the two.

Alexander and Crutcher (1990b) have reported a large number of the neurons in supplementary and primary motor cortex (see also Martin and Ghez, 1985), as well as in the putamen, that reflect the spatial location (or direction) of an instruction stimulus rather than the target (or direction) of an upcoming limb movement. Our findings for PM (Table 3) are consistent with theirs. In both experiments, a given movement was guided by more than one spatially different stimulus and was associated with significantly different levels of activity, perhaps reflecting stimulus location. For some of our delay-period cells $(54 \%)$, the activity does appear to reflect the location of the prime stimulus; that is, the cell's preferred directions in the two conditions are within $45^{\circ}$ of each other. For other neurons (46\%), however, a more complex relationship applies. By contrast, Crammond and Kalaska (1990) suggested that, with the exception of a brief period immediately after a cue, PM activity evolves during a delay period to reflect the direction of limb movement. This result is similar to that reported by Georgopoulos et al. (1989; Lurito et al., 1991) for primary motor cortex. They showed that the neuronal population vector evolves to reflect the limbmovement direction, though it initially reflects the direction of the instructing stimulus in a task that required a monkey to move in a direction $90^{\circ}$ from a visual stimulus. Lurito et al. also found that $41 \%$ of primary motor cortex cells had significantly different activity when the same movement was instructed by two different stimulus locations.

Thus, there are several reports that neurons in motor cortical fields show certain specificities or conditionalities in the relation of neuronal activity to motor responses (Alexander and Crutcher, 1990b; Lurito et al., 1991). One way of viewing these conditionalities, including the position effect in our incompatible condition, is that the neuronal activity reflects the selection and control of movement, but only in certain situations. For example, Tanji and his colleagues (Tanji and Kurata, 1982; Kurata and Tanji, 1986) have shown that some cells in PM and the supplementary motor cortex show activity before movements triggered by stimuli one sensory modality but not when triggered by stimuli of a different modality. Similarly, some neurons appear to be related to movements of the contralateral limb, but only in the absence of ipsilateral limb movement (Tanji et al., 1988), although the contralateral muscles have the same activity in both circumstances. The spatial tuning observed in PM and PF during movements to a repetitive target, that is, neuronal specificity based on triggering stimulus location, appears to resemble the specificity that depends on stimulus modality and movement combinations. Thus, we propose that the neuronal discharge in PM reflects the selection of an action under a certain set of circumstances and not the selection of a movement per se (see also Mitz et al., 1991).

\section{References}

Alexander GE, Crutcher MD (1990a) Preparation for movement: neural representations of intended direction in three motor areas of the monkey. J Neurophysiol 64:133-150.

Alexander GE, Crutcher MD (1990b) Neural representation of the target (goal) of visually guided arm movements in three motor areas of the monkey. J Neurophysiol 64:164-178.

Bakay Pragay E, Mirsky AF, Nakamura RF (1987) Attention-related unit activity in the frontal association cortex during a go/no-go visual discrimination task. Exp Neurol 96:481-500.

Barbas H, Pandya DN (1987) Architecture and frontal cortical connections of the premotor cortex (area 6) in the rhesus monkey. J Comp Neurol 256:211-228.

Barbas H, Pandya DN (1989) Architecture and intrinsic connections of the prefrontal cortex in the rhesus monkey. J Comp Neurol 286: 353-375.

Barone P, Joseph J-P (1989) Prefrontal cortex and spatial sequencing in macaque monkey. Exp Brain Res 78:447-464.

Bauswein E, Fromm C, Werner W, Zeiman U (1991) Phasic and tonic responses of premolor and primary motor cortex neurons to torque changes. Exp Brain Res 86:303-310.

Boch RA, Goldberg ME (1989) Participation of prefrontal neurons in the preparation of visually guided eye movements in the rhesus monkey. J Neurophysiol 61:1064-1084.

Brodmann K (1905) Beiträge zur histologischen Lokalisation der Grosshirnrinde. III. Die Rindenfelder der niederen Affen. J Psychol Neurol 4:177-226.

Brodmann K (1909) Vergleichende Lokalisationslehre der Grosshirnrinde in ihren Prinzipien dargestellt auf Grund des Zellenbaues. Leipzig: Barth.

Bruce CJ, Goldberg ME (1985) Primate frontal eye fields. I. Single neurons discharging before saccades. J Neurophysiol 53:603-635.

Burbaud P, Doegle C, Gross C, Bioulac B (1991) A quantitative study of neuronal discharge in areas 5,2 , and 4 of the monkey during fast arm movements. J Neurophysiol 66:429-443.

Burnod Y, Grandguillaume P, Otto I, Ferraina S, Johnson PB, Caminiti $R$ (1992) Visuomotor transformations underlying arm movements toward visual targets: a neural network model of cerebral cortical operations. J Neurosci 12:1435-1453.

Caminiti R, Johnson PB, Burnod Y, Galli C, Ferraina AS (1990) Shift of preferred directions of premotor cortical cells with arm movements performed across the workspace. Exp Brain Res 83:228-232.

Caminiti R, Johnson PB, Urbano A (1991) Making arm movements within different parts of space: the premotor and motor cortical representation of a coordinate system for reaching to visual targets. J Neurosci 11:1182-1197.

Crammond DJ, Kalaska JF (1990) Cortical neuronal activity recorded in a delay task that dissociates location of cue stimulus and movement endpoint. Soc Neurosci Abstr 16:423.

Crammond DJ, Kalaska JF (1991) Preparatory neuronal activity in premotor cortex during an instructed-delay period: relation to contraand ipsilateral arm movements. Soc Neurosci Abstr 17:308.

di Pellegrino G, Wise SP (1991a) A neurophysiological comparison of three distinct regions of the primate frontal lobe. Brain 114:951978.

di Pellegrino G, Wise SP (199 1b) Primate frontal cortex: visuospatial vs. visuomotor activity. Soc Neurosci Abstr 17:1112.

Fogassi L, Gallese V, di Pellegrino G, Fadiga L, Gentilucci M, Luppino 
G, Matelli M, Pedotti A, Rizzolatti G (1992) Space coding by premotor cortex. Exp Brain Res 89:686-690.

Funahashi S, Goldman-Rakic PS (1990) Delay-period activity of prefrontal neurons in delayed saccade and anti-saccade tasks. Soc Neurosci Abstr 16:1223.

Funahashi S, Bruce CJ, Goldman-Rakic PS (1989) Mnemonic coding of visual space in the monkey's dorsolateral prefrontal cortex. J Neurophysiol 61:331-349.

Funahashi S, Bruce CJ, Goldman-Rakic PS (1990) Visuospatial coding in primate prefrontal neurons revealed by oculomotor paradigms. J Neurophysiol 63:814-831.

Funahashi S, Bruce CJ, Goldman-Rakic PS (1991) Neuronal activity related to saccadic eye movements in the monkey's dorsolateral prefrontal cortex. J Neurophysiol 65:1464-1483.

Fuster JM (1973) Unit activity in prefrontal cortex during delayedresponse performance: neuronal correlates of transient memory. $J$ Neurophysiol 36:61-78.

Fuster JM, Alexander GE (1971) Neuron activity related to shortterm memory. Science 173:652-654.

Gentilucci M, Fogassi L, Luppino G, Matelli M, Camarda R, Rizzolatti G (1988) Functional organization of inferior area 6 in the macaque monkey. I. Somatotopy and the control of proximal movements. Exp Brain Res 71:475-490.

Georgopoulos A, Massey JT (1987) Cognitive spatial-motor processes I. The making of movements at various angles from a stimulus direction. Exp Brain Res 65:361-370.

Georgopoulos AP, Kalaska JF, Caminiti R, Massey JT (1982) On the relations between the direction of two-dimensional arm movements and cell discharge in primate motor cortex. J Neurosci 11:1527-1537.

Georgopoulos AP, Lurito JT, Petrides M, Schwartz AB, Massey JT (1989) Mental rotation of the neuronal population vector. Science 243:234-236.

Godschalk M, Lemon RN (1983) Involvement of monkey premotor cortex in the preparation of arm movements. Exp Brain Res 7:114 119.

Godschalk M, Lemon RN, Niji HGT, Kuypers HGJM (1981) Behaviour of neurons in monkey peri-arcuate and precentral cortex before and during visually guided arm and hand movements. Exp Brain Res 44:113-116.

Godschalk M, Lemon RN, Kuypers HGJM, van der Steen J (1985) The involvement of monkey premotor cortex neurones in preparation of visually cued arm movements. Behav Brain Res 18:143-157.

Hocherman S, Wise SP (1991) Effects of hand movement path on motor cortical activity in awake, behaving rhesus monkeys. Exp Brain Res 83:285-302.

Joseph JP, Barone P (1987) Prefrontal unit activity during a delayed oculomotor task in the monkey. Exp Brain Res 67:460-468.

Kalaska J, Crammond D (1992) Cerebral cortical mechanisms of reaching movements. Science 255:1517-1523.

Kojima S (1980) Prefrontal unit activity in the monkey: relation to visual stimuli and movements. Exp Neurol 69:110-123.

Kojima S, Goldman-Rakic PS (1982) Delay-related activity of prefrontal neurons in rhesus monkeys performing delayed response. Brain Res 248:43-50.

Kojima S, Goldman-Rakic PS (1984) Functional analysis of spatially discriminative neurons in prefrontal cortex of rhesus monkey. Brain Res 291:229-240.

Kubota K, Funahashi S (1982) Direction-specific activities of dorsolateral prefrontal and motor cortex pyramidal tract neurons during visual tracking. J Neurophysiol 47:362-376.

Kubota K, Hamada I (1978) Visual tracking and neuron activity in the postarcuate area in monkeys. J Physiol (Paris) 74:297-312.

Kubota K, Niki H (1971) Prefrontal cortical unit activity and delayed alternation performance in monkeys. J Neurophysiol 34:337-347.

Kubota K, Iwamoto T, Suzuki H (1974) Visuokinetic activities of primate prefrontal neurons during delayed-response performance. J Neurophysiol 37:1197-1212.

Kurata K, Tanji J (1986) Premotor cortex neurons in macaques: activity before distal and proximal forelimb movements. J Neurosci 6:403-411.

Kurata K, Wise SP (1988a) Premotor cortex of rhesus monkeys: setrelated activity during two conditional motor tasks. Exp Brain Res 69:327-343.

Kurata K, Wise SP (1988b) Premotor and supplementary motor cortex in rhesus monkeys: neuronal activity during externally- and internally-instructed motor tasks. Exp Brain Res 72:237-248.

Kwan HC, MacKay WA, Murphy JT, Wong YC (1981) Distribution of responses to visual cues for movement in precentral cortex of awake primates. Neurosci Lett 24:123-128.

Kwan HC, MacKay WA, Murphy JT, Wong YC (1985) Properties of visual cue responses in primate precentral cortex. Brain Res 343:2435

Lurito JT, Georgakopoulos T, Georgopoulos AP (1991) Cognitive spatial motor processes. 7. The making of movements at an angle from a stimulus direction: studies of motor cortical activity at the single cell and population levels. Exp Brain Res 87:562-580.

Martin JH, Ghez C (1985) Task-related coding of stimulus and response in cat motor cortex. Exp Brain Res 57:427-442.

Mauritz K-H, Wise SP (1986) Premotor cortex of rhesus monkey: neuronal activity in anticipation of prcdictable environmental events. Exp Brain Res 61:229-244.

Mikami A, Ito S, Kubota K (1982) Visual response properties of dorsolateral prefrontal neurons during visual fixation task. J Neurophysiol 47:593-605.

Mitz AR, Godschalk M, Wise SP (1991) Learning-dependent neuronal activity in the premotor cortex of rhesus monkeys. J Neurosci 11: $1855-1872$.

Mushiake H, Inase M, Tanji J (1991) Neuronal activity in the primate premotor, supplementary, and precentral motor cortex during visually guided and internally determined sequential movements. J Neurophysiol 66:705-718.

Niki H (1974a) Prefrontal unit activity during delayed alternation in the monkey. I. Relation to direction of response. Brain Res $68: 185$ 196.

Niki H (1974b) Prefrontal unit activity during delayed alternation in the monkey. II. Relation to absolute versus relative direction of response. Brain Res 68:197-204.

Niki H (1974c) Differential activity of prefrontal units during right and left delayed response trials. Brain Res 70:346-349.

Niki H, Watanabe M (1976) Prefrontal unit activity and delayed response: relation of cue location versus direction of response. Brain Res 105:79-88.

Okano K (1992) Temporal priority of premotor cortex over nearby areas in receiving visual cues in primates. Neuroreport 3:389-392.

Okano K, Tanji J (1987) Neuronal activities in the primate motor fields of the agranular frontal cortex preceding visually triggered and self-paced movement Exp Brain Res 66:155-166.

Requin J, Riehle A, Seal J (1988) Neuronal activity and information processing in motor control: from stages to continuous flow. Biol Psychol 26:179-198.

Riehle A (1991) Visually induced signal-locked neuronal activity changes in precentral motor areas of the monkey: hierarchical progression of signal processing. Brain Res 540:131-137.

Riehle A, Requin J (1989) Monkey primary motor and premotor cortex: single-cell activity related to prior information about direction and extent of an intended movement. J Neurophysiol 61:534-549.

Rizzolatti G, Scandolara C, Matelli M, Gentilucci M (1981) Afferent properties of periarcuate neurons in macaque monkeys. 2. Visual responses. Behav Brain Res 2:147-163.

Rizzolatti G, Gentilucci M, Fogassi L, Luppino G, Matelli M, PonzoniMaggi S (1987) Neurons related to goal-directed motor acts in infcrior area 6 of the macaque monkey. Exp Brain Res 67:220-224.

Rizzolatti G, Camarda R, Fogassi L, Gentilucci M, Luppino G, Matelli $M$ (1988) Functional organization of inferior area 6 in the macaque monkey. II. Area F5 and the control of distal movements. Exp Brain Res 71:491-507.

Sakai M (1978) Single unit activity in a border area between the dorsal prefrontal and premotor regions in the visually conditioned motor task of monkeys. Brain Res 147:377-383.

Sasaki K, Gemba H, Tsujimoto T (1990) Cortical field potential associated with hand movement on warning-imperative visual stimulus and cerebellum in the monkey. Brain Res 519:343-346.

Seal J, Commenges D (1985) A quantitative analysis of stimulus- and movement-related responses in the posterior parietal cortex of the monkey. Exp Brain Res 58:144-153.

Seal J, Commenges D, Salamon R, Bioulac B (1983) A statistical method for the estimation of neuronal response latency and its functional interpretation. Brain Res 278:382-386.

Tanji J, Kurata K (1982) Comparison of movement-related activity in two cortical motor areas of primates. J Neurophysiol 48:633-653.

Tanji J, Okano K, Sato KC (1988) Neuronal activity in cortical motor areas related to ipsilateral, contralateral and bilateral digit movements of the monkey. J Neurophysiol 60:325-343.

Vaadia E, Benson DA, Hienz RD, Goldstein MH (1986) Unit study 
of monkey frontal cortex: active localization of auditory and of visual stimuli. J Neurophysiol 56:934-952.

Vaadia E, Kurata K, Wisc SP (1988) Neuronal activity preceding directional and nondirectional cues in the premotor cortex of rhesus monkeys. Somatosens Mot Res 6:207-230.

Walker E (1940) A cytoarchitectural study of the prefrontal area of the macaque monkey. J Comp Neurol 98:59-86.

Wannier TMJ, Maier MA, Hepp-Reymond M-C (1989) Responses of motor cortex neurons to visual stimulation in the alert monkey. Neurosci Lett 98:63-68.

Watanabe M (1986a) Prefrontal unit activity during delayed conditional go/no-go discrimination in the monkey. I. Relation to the stimulus. Brain Res 382:1-14.

Watanabe M (1986b) Prefrontal unit activity during delayed conditional go/no-go discrimination in the monkey. II. Relation to go and no-go responses. Brain Res 382:15-27.

Watanabe M (1989) The appropriateness of behavioral responses coded in post-trial activity of primate prefrontal units. Neurosci Lett 101: 113-117

Watanabe M (1990) Prefrontal unit activity during associative learning in the monkey. Exp Brain Res 80:296-309.

Watanabe M (1992) Frontal units of the monkey coding the associative significance of visual and auditory stimuli. Exp Brain Res 89:233247.
Weinrich M, Wise SP (1982) The premotor cortex of the monkey. J Neurosci 2:1329-1345.

Weinrich M, Wise SP, Mauritz K-H (1984) A neurophysiological analysis of the premotor cortex of the monkey. Brain 107:385-414.

Werner W, Bauswein E, Fromm C (1991) Static firing rates of premotor and primary motor cortical neurons associated with torque and joint position. Exp Brain Res 86:293-302.

Wise SP (1984) Nonprimary motor cortex and its role in the cerebral control of movement. In: Dynamic aspects of neocortical function (Edelman G, Cowan WM, Gall E, eds), pp 525-555. New York: Wiley.

Wise SP (1985) The primate premotor cortex: past, present, and preparatory. Annu Rev Neurosci 8:1-19.

Wise SP, Mauritz K-H (1985) Set-related neuronal activity in the premotor cortex of rhesus monkeys: effects of changes in motor set. Proc R Soc Lond [Biol] 223:331-354.

Wise SP, di Pellegrino G, Boussaoud D (1992) Primate premotor cortex: dissociation of visuomotor from sensory signals. J Neurophysiol 68:969-972.

Yajeya J, Quintana J, Fuster J (1988) Prefrontal representation of stimulus attributes during delay tasks. II. The role of behavioral significance. Brain Res 474:222-230. 